\title{
Enhancements of the refractory submicron aerosol fraction in the Arctic polar vortex: feature or exception?
}

\author{
R. Weigel ${ }^{1}$, C. M. Volk ${ }^{2}$, K. Kandler ${ }^{3}$, E. Hösen ${ }^{2, *}$, G. Günther ${ }^{4}$, B. Vogel ${ }^{4}$, J.-U. Grooß ${ }^{4}$, S. Khaykin ${ }^{5, * *}$, \\ G. V. Belyaev ${ }^{6}$, and S. Borrmann ${ }^{1,7}$ \\ ${ }^{1}$ Institut für Physik der Atmosphäre, Johannes Gutenberg-Universität, Mainz, Germany \\ ${ }^{2}$ Department of Physics, University of Wuppertal, Wuppertal, Germany \\ ${ }^{3}$ Institut für Angewandte Geowissenschaften, Technische Universität Darmstadt, Germany \\ ${ }^{4}$ Institut für Energie- und Klimaforschung (IEK-7), Forschungszentrum Jülich, Jülich, Germany \\ ${ }^{5}$ Central Aerological Observatory, Dolgoprudny, Moskow Region, Russia \\ ${ }^{6}$ Myasishchev Design Bureau, Zhukovsky-5, Moscow Region, Russia \\ ${ }^{7}$ Partikelchemie, Max-Planck-Institut für Chemie, Mainz, Germany \\ * now at: Institut für Ozeanographie, Universität Hamburg, Hamburg, Germany \\ *** now at: CNRS/INSU, LATMOS-IPSL, Université de Versailles St. Quentin, Guyancourt, France
}

Correspondence to: R. Weigel (weigelr@uni-mainz.de)

Received: 31 March 2014 - Published in Atmos. Chem. Phys. Discuss.: 16 April 2014

Revised: 10 October 2014 - Accepted: 13 October 2014 - Published: 25 November 2014

\begin{abstract}
In situ measurements with a four-channel stratospheric condensation particle counter (CPC) were conducted at up to $20 \mathrm{~km}$ altitude on board the aircraft M-55 Geophysica from Kiruna, Sweden, in January through March (EUPLEX 2003, RECONCILE 2010) and in December (ESSenCe 2011). During all campaigns air masses from the upper stratosphere and mesosphere were subsiding inside the Arctic winter vortex, thus initializing a transport of refractory aerosol into the lower stratosphere $(\Theta<500 \mathrm{~K})$. The strength and extent of this downward transport varied between the years depending on the dynamical evolution of the vortex. Inside the vortex and at potential temperatures $\Theta \geq 450 \mathrm{~K}$ around 11 submicron particles per $\mathrm{cm}^{3}$ were generally detected. Up to 8 of these 11 particles per $\mathrm{cm}^{3}$ were found to contain thermo-stable (at $250^{\circ} \mathrm{C}$ ) residuals with diameters of $10 \mathrm{~nm}$ to about $1 \mu \mathrm{m}$. Particle mixing ratios $\left(150 \mathrm{mg}^{-1}\right)$ and fractions of non-volatile particles ( $75 \%$ of totally detected particles) exhibited highest values in air masses having the lowest content of nitrous oxide $\left(70 \mathrm{nmol} \mathrm{mol}^{-1}\right.$ of $\left.\mathrm{N}_{2} \mathrm{O}\right)$. This indicates that refractory aerosol originates from the upper stratosphere or the mesosphere. Derived from the mixing ratio of the simultaneously measured long-lived tracer $\mathrm{N}_{2} \mathrm{O}$, an empirical index serves to differentiate probed air masses according to their origin: in-
\end{abstract}

side the vortex, the vortex edge region, or outside the vortex. Previously observed high fractions of refractory submicron aerosol in the 2003 Arctic vortex were ascribed to unusually strong subsidence during that winter. However, measurements under perturbed vortex conditions in 2010 and during early winter in December 2011 revealed similarly high values. Thus, the abundance of refractory aerosol in the lower stratosphere within the Arctic vortices appears to be a regular feature rather than the exception. During December, the import from aloft into the lower stratosphere appears to be developing; thereafter the abundance of refractory aerosol inside the vortex reaches its highest levels in March. The correlations of refractory aerosol with $\mathrm{N}_{2} \mathrm{O}$ suggest that, apart from mean subsidence, diabatic dispersion inside the vortex significantly contributes to the transport of particles to the Arctic lower stratosphere. A measurement-based estimate of the total mass of refractory aerosol inside the vortex is provided for each campaign. Based on the derived increase of particle mass in the lower stratospheric vortex $(100-67 \mathrm{hPa}$ pressure altitude) by a factor of 4.5 between early and late winter, we estimate the total mass of mesospheric particles deposited over the winter 2009/2010 in the entire Arctic vortex to range between $77 \times 10^{3}$ and $375 \times 10^{6} \mathrm{~kg}$. This estimate is compared with the expected atmospheric influx of 
meteoritic material $\left(110 \pm 55 \times 10^{3} \mathrm{~kg}\right.$ per day $)$. Such estimates at present still hold considerable uncertainties, which are discussed in this article. Nevertheless, the results enable placing constraints on the shape of the so far unknown size distribution of refractory aerosol within the vortex.

\section{Introduction}

In situ measurements of the aerosol vertical distribution inside the Arctic winter vortex of 1989 revealed an increase of the mixing ratios of sub-micrometer sized particles with altitude (Wilson et al., 1990). Also in the Arctic (from Kiruna, Northern Sweden), in the year 2003, similar vertical profiles were observed (Curtius et al., 2005) and here it was reported that an increase of particle concentrations coincided with an increasing fraction of non-volatile aerosol compounds. Both studies demonstrated that the abundance of particles is closely linked to air mass subsidence inside the vortex from upper stratospheric or mesospheric altitudes down to the Arctic lower stratosphere. Such particles provide surfaces for heterogeneous reactions and deposition of condensable gases. Thus, their presence in the polar winter stratosphere may play a crucial role in the formation of polar stratospheric clouds (PSCs) (Voigt et al., 2005; Hoyle et al., 2013; Engel et al., 2013) or in heterogeneous chemistry (Peter, 1997; Solomon, 1999; Peter and Grooß, 2012) connected to ozone depletion. A downward import of non-volatile particles potentially occurring on a regular basis inside the vortex could imply an important natural process linked to atmospheric ozone chemistry.

\subsection{Origin of vortex aerosol}

The major import of refractory aerosol material into the upper atmosphere is expected to occur with the entry of meteoroids with particle diameter $\left(d_{\mathrm{p}}\right)$ smaller than $1 \mathrm{~mm}$, particularly of interplanetary dust particles (IDPs; $d_{\mathrm{p}}<1 \mu \mathrm{m}$ ), and by the ablation of meteoroids penetrating the atmosphere (von Zahn, 2005). Results from single particle chemical analyses of aerosols with diameters from $300 \mathrm{~nm}$ to $1 \mu \mathrm{m}$ in the Upper Troposphere/Lowermost Stratosphere (UT/LS) at midlatitudes and in the tropics suggest meteoritic ablation material is included in a large fraction of stratospheric particles (Murphy et al., 2013, and references therein). The total mass flux of meteoritic material into the atmosphere is estimated by various studies with different approaches. These estimates range from less than $20 \times 10^{3} \mathrm{~kg}$ per day (Plane, 2004) to fluxes between $20 \times 10^{3} \mathrm{~kg}$ and $100 \times 10^{3} \mathrm{~kg}$ per day (Cziczo et al., 2001; Gabrielli et al., 2004) and to $110 \pm 55 \times 10^{3} \mathrm{~kg}$ per day (Love and Brownlee, 1993; Peucker-Ehrenbrink, 1996). The last value currently seems to be the most accepted, according to the review by von Zahn (2005). Plane (2012) presents a detailed discussion of these fluxes concerning plausibility and consistence with observa- tions, and he limits the uncertainty in the flux estimates provided in the literature to a factor of 10 in the order of magnitude between $\sim 10$ to $100 \times 10^{3} \mathrm{~kg}$ per day. The review by Plane (2012) clearly shows how uncertain the knowledge of the true meteoritic influx is. The value provided by Love and Brownlee (1993) was obtained by assuming a certain velocity distribution for the particles hitting an impact detector. The study of Janches et al. (2000) investigated the effective mass loss of meteoroids due to deceleration dependent on a broader range of penetration velocities, which potentially yields a refinement of the results of Love and Brownlee (1993). Nevertheless, we will refer here to the most accepted value of $110 \times 10^{3} \mathrm{~kg}$ per day for comparing the results of our estimates, while bearing in mind that an uncertainty of one order of magnitude needs to be considered for the value of the meteoritic influx into the atmosphere (Plane, 2012).

A certain fraction of this total daily influx is assumed to experience little or no ablation because the meteoritic bodies are too small. With a mass below $10^{-11} \mathrm{~kg}$, their sizes are usually smaller than $20 \mu \mathrm{m}$ in diameter (Jones and Kaiser, 1966). Such small objects are not sufficiently heated by friction with atmospheric air molecules when entering the atmosphere. For large meteoroid masses $\left(>100 \times 10^{3} \mathrm{~kg}\right.$ and $d_{\mathrm{p}}>4 \mathrm{~m}$ ) the number of atmosphere-hitting events of about one per year (von Zahn, 2005) is too small to significantly contribute to the total influx of meteoritic material. Furthermore, von Zahn (2005) estimated that objects in the mass range of $10^{-11}$ to $10^{-5} \mathrm{~kg}$, correspondent to diameters of $20 \mu \mathrm{m}-2 \mathrm{~mm}$, contribute the major part of the total influx. These predominantly sub-millimeter sized particles are nearly fully vaporized mainly in the altitude range between 75 and $120 \mathrm{~km}$ (Megner et al., 2008). The ablation process is assumed to release atomic metal vapors that re-condense to form nanometer sized, long-lived meteoritic smoke particles (MSPs) (Hunten et al., 1980; Kalashnikova et al., 2000; Plane, 2004). Experimental studies provided evidence for the presence of meteoritic ablation material in the mesosphere (Rapp et al., 2007; Rapp and Strelnikova, 2009; Strelnikova et al., 2009). The size of MSPs may range from clusters of molecules with diameters of about $1 \mathrm{~nm}$ to a few hundred nanometers. Numerical studies investigate the processing and transport of the initially ultrafine $\left(d_{\mathrm{p}}<10 \mathrm{~nm}\right)$ refractory MSPs along their atmospheric residence (Bardeen et al., 2008; Megner et al., 2008; Dhomse et al., 2013). These studies also take into account that MSP coagulate to form larger particles (secondary cosmic aerosols with $d_{\mathrm{p}}>10 \mathrm{~nm}$ ) as well as sedimentation and deposition processes that remove the MSPs. Laboratory as well as modeling studies particularly investigate the potential of MSPs to act as condensation surfaces for water vapor $\left(\mathrm{H}_{2} \mathrm{O}\right)$ to form ice clouds (Saunders et al., 2010) and their impact on stratospheric $\mathrm{H}_{2} \mathrm{SO}_{4}$ processing on global scales (Saunders et al., 2012). The size distribution of secondary cosmic aerosols overlaps with the size distribution of IDPs that enter the atmosphere without strong thermal alteration. As a result, the size distribution of 
refractory aerosol in the upper atmosphere is expected to be restricted to the particle diameter range of $1 \mathrm{~nm}$ to $20 \mu \mathrm{m}$. Particles with diameter larger than $1 \mu \mathrm{m}$ undergo relatively fast removal due to sedimentation. The meteoritic influx is supposedly a continuous process; consequently it can be assumed that sedimentation of the larger particles through the region of our measurements is continuously occurring, ultimately resulting in stationary equilibrium concentrations. Therefore, we can expect to find particles between the minimum size determined by condensation/coagulation and the maximum size determined by the non-ablation.

In the lower diameter range $\left(0.1 \mu \mathrm{m}<d_{\mathrm{p}}<1 \mu \mathrm{m}\right)$ the particles have atmospheric residence times of several months or, if even smaller, of years. The study of Dhomse et al. (2013) investigated the distribution and transport of ${ }^{238} \mathrm{PuO}_{2}$ that was accidentally released at an altitude of $46-60 \mathrm{~km}$ in the year 1964 due to the re-entry and burn-up of a satellite power unit. The modeled distribution of ${ }^{238} \mathrm{PuO}_{2}$ in the atmosphere and its deposition on the Earth's surface until 1974 suggest up to 10 years of atmospheric residence, in agreement with observations. Atmospheric residences of the same order of magnitude can most likely be transferred to ablation material from meteoroids. Once these particles enter regions in the atmosphere with saturated vapors, for example of $\mathrm{H}_{2} \mathrm{SO}_{4}$, nitric acid $\left(\mathrm{HNO}_{3}\right)$ or water $\left(\mathrm{H}_{2} \mathrm{O}\right)$, heterogeneous condensation leads to particle coating and growth, and finally their removal due to increased sedimentation speed or, at some point, even incorporation in clouds. At midlatitudes the particles are quickly removed from the stratosphere, entering the troposphere by isentropic mixing induced by breaking Rossby waves (Holton et al., 1995; Dhomse et al., 2013).

Recently published results from balloon-borne measurements in the Antarctic winter stratosphere (Campbell and Deshler, 2014) suggest that new particle formation (NPF) may provide an additional regional source of volatile particles in the vortex. At altitudes of $21-24 \mathrm{~km}$ aerosol number concentrations were found to be increased by a factor of 5 to 10 , compared to background states concurrently with low fractions of less than $20 \%$ of refractory residuals. These measurements indicate relatively weak particle formation efficiencies compared to excessive NPF events observed elsewhere in the UT/LS (e.g., Brock et al., 1995; Weigel et al., 2011). Nevertheless, the comparably moderate abundance of particles most likely caused by NPF in the Antarctic stratosphere (Campbell and Deshler, 2014) may last for longer duration and may provide persistent fields with enhanced presence of particles and thus reaction surfaces. However, above $24 \mathrm{~km}$ in the Antarctic winter stratosphere, large fractions of non-volatile particles of up to $80 \%$ are indicated (Campbell and Deshler, 2014). The same study shows that with an averaged fraction of about $60 \%$ of non-volatile particles the abundance of refractory material in the Antarctic winter stratosphere is significantly increased compared to the same altitude range at midlatitudes.

\subsection{Vortex-driven downward transport}

The stratospheric vortex development causing large scale subsidence of air masses in the polar region during winter is a very efficient vertical transport pathway over a wide range of atmospheric altitudes. As the vortex-induced downward transport drives the import of non-volatile particles from altitudes of the upper stratosphere or mesosphere (Curtius et al., 2005) it is commonly assumed that the non-volatile particles to a large extent originate from space. Other studies related to the Arctic vortex (e.g., Randall et al., 2006; Vogel et al., 2008) also show that $\mathrm{NO}_{\mathrm{x}}$-rich air masses from the upper stratosphere and mesosphere, caused by energetic particle precipitation (EPP), are transported downward in a strong, well-isolated vortex. These studies support the hypothesis that the polar vortex generally acts as a major driver for the descent of air from the mesosphere and upper stratosphere. Therefore, it is expected that the Antarctic vortex air mass subsidence likewise supports this downward transport. According to model studies of vertical vortex transport (e.g., Plumb et al., 2002) most of the content of the mesosphere is ingested by the vortex towards the end of a polar winter and the signatures of mesospheric air are discernible down to the vortex bottom. Balloon-borne observations of carbon monoxide (CO) have traced mesospheric origin down to levels of $500 \mathrm{~K}$ of potential temperature (see Fig. 6 in Plumb et al., 2002), which is above the maximum ceiling of the M55 Geophysica. The mean large-scale subsidence inside the vortex apparently occurs most efficiently at altitudes above $500 \mathrm{~K}$. In fact, below $500 \mathrm{~K}$ mean diabatic subsidence is typically insufficient to transport the bulk air mass from $500 \mathrm{~K}$ (or above) to $400 \mathrm{~K}$ over the course of the winter (Greenblatt et al., 2002a; Werner et al., 2010). Vertical transport of refractory aerosol to below $500 \mathrm{~K}$ may thus be mainly driven by diabatic dispersion within the vortex rather than by mean diabatic subsidence. Diabatic dispersion may be understood as a gradual vertical mixing resulting from differential subsidence together with horizontal mixing (Plumb, 2007). This process has been found to be consistent with the development of observed tracer distributions inside the Arctic vortex (Ray et al., 2002).

\subsection{Aerosol particle microphysics}

The polar winter vortices in general could act as the major drain pathway of aerosol from the upper stratosphere and mesosphere towards the UT/LS, followed by material removal onto the Earth's surface. If the subsidence of refractory particles was a regular feature this could play an important role for heterogeneous PSC formation, as these particles provide surfaces for condensation (cf. Hoyle et al., 2013; Engel et al., 2013; Molleker et al., 2014). The availability of reaction surfaces is of particular importance in times of volcanic quiescence when the stratospheric Junge aerosol layer reaches relatively low particle concentrations; for example 
in 1997, 6 years after the Mt. Pinatubo eruption (Borrmann et al., 2000). It seems very plausible that such particles support other microphysical processes, such as heterogeneous freezing, although bulk freezing experiments (Biermann et al., 1996) indicate minor importance. PSCs promote denitrification of the polar lower stratosphere as demonstrated for the RECONCILE (cf. Sect. 3) winter (Grooß et al., 2014; Woiwode et al., 2014; Molleker et al., 2014). Denitrification essentially contributes to ozone loss in the polar winter stratosphere (Fahey et al., 1990; Mann et al., 2003; Waibel et al., 1999).

In this study we address the question whether the observed import of refractory particles into the Arctic lower stratosphere was an exceptional event in 2003 (Curtius et al., 2005; Engel et al., 2006) or rather a feature that regularly occurs in Arctic winters. Furthermore, from the vertical distribution of refractory aerosol within the vortex obtained from three campaigns, we derive parameterizations which may be suitable for numerical simulations of heterogeneous PSC formation and other aerosol related processes. Finally, we estimate the total refractory aerosol mass inside the lower Arctic vortex and - by extrapolation of our in situ measurements - assess it in the context of the northern hemispheric daily mass influx of meteoritic material. Based on these considerations we suggest that constraints may be placed on the size distribution of refractory aerosol within the Arctic vortex, which is so far unknown.

\section{Instruments and methods}

\subsection{Submicron particles}

Aerosol concentrations were measured by a four-channel continuous flow condensation particle counter COPAS (COndensation PArticle counting System) using a chlorofluorocarbon (FC-43) as working liquid. COPAS measurements and data storage occur at a frequency of $1 \mathrm{~Hz}$. Three of the four COPAS channels operate with different $50 \%$ detection particle diameters $d_{\mathrm{p} 50}$ (i.e., $6 \mathrm{~nm}, 10 \mathrm{~nm}$ and $15 \mathrm{~nm}$ ). The fourth COPAS channel (with $d_{\mathrm{p} 50}=10 \mathrm{~nm}$ ) counts aerosol particles after they have passed a heated sample flow line resulting in measured particle mixing ratios of non-volatile (nv) or refractory particles (e.g., soot, mineral dust, metallic aerosol material, etc.). At an operational temperature of $250^{\circ} \mathrm{C}$ and over the pressure range of 70-300 hPa, this aerosol pre-heater volatilizes more than $98 \%$ of $\mathrm{H}_{2} \mathrm{SO}_{4}-\mathrm{H}_{2} \mathrm{O}$ particles (Weigel et al., 2009).

The entry of the forward facing aerosol inlet of COPAS is positioned well outside the aircraft's boundary layer. The inlet consists of two serial diffusors which decelerate the air from the free flow to pumping velocity at near-isokinetic conditions. For stratospheric particle concentrations the COPAS measurement uncertainty is about $10 \%$, resulting from particle counting statistics and uncertainties in the volume flow.
The measurement characteristics of COPAS are described in detail by Weigel et al. (2009) and its performance is demonstrated by several studies (Curtius et al., 2005; Borrmann et al., 2010; Frey et al., 2011; Weigel et al., 2011).

Particle concentrations are initially measured in particle number per cubic centimeter of sampled air, but are presented here as mixing ratio $N$ in units of particles per milligram of air $\left(\mathrm{mg}^{-1}\right)$ for comparing measurements from different pressure altitudes and for correlations with tracer mixing ratios. In the following, $N_{10}$ denotes the mixing ratio of particles with diameters larger than $10 \mathrm{~nm}$ up to about $1 \mu \mathrm{m}$. $N_{10} \mathrm{nv}$ refers to the mixing ratio of non-volatile particles in the same size range. The fraction $f$ of non-volatile particles is given as the ratio of $N_{10} \mathrm{nv}$ and $N_{10}$ in \% as only non-volatile particles with sizes $d_{\mathrm{p}}>10 \mathrm{~nm}$ are detected. The measurement of particles with $d_{\mathrm{p}}>6 \mathrm{~nm}$ and $d_{\mathrm{p}}>15 \mathrm{~nm}$ aims in principle at the identification of recently occurred NPF (cf. Weigel et al., 2011). However, throughout all measurements discussed here, no such NPF event was identified.

\subsection{Dynamic tracer nitrous oxide}

Nitrous oxide $\left(\mathrm{N}_{2} \mathrm{O}\right)$, a long-lived atmospheric tracer, is measured in situ on board the M-55 Geophysica by the HAGAR (High Altitude Gas AnalyzeR) instrument (Werner et al., 2010; Homan et al., 2010). $\mathrm{N}_{2} \mathrm{O}$ is detected by gas chromatography with electron capture detection (GC/ECD) along with other long-lived species like chlorofluorocarbons (CFCs), sulfur hexafluoride $\left(\mathrm{SF}_{6}\right)$ and methane $\left(\mathrm{CH}_{4}\right)$ with a temporal resolution of $90 \mathrm{~s}$. The mean precision for the $\mathrm{N}_{2} \mathrm{O}$ measurements, given in $\%$ of the tropospheric value $(\sim 320 \mathrm{ppb})$, is below $0.5 \%$ for all three campaigns, except the first four flights during EUPLEX (cf. Sect. 3) for which it is $1-1.3 \%$. For most flights it is in fact below $0.3 \%$.

$\mathrm{N}_{2} \mathrm{O}$ is generated at the surface and has its sink at high altitudes, generally above the tropopause, where with increasing altitude the $\mathrm{N}_{2} \mathrm{O}$ molecules are destroyed by UV photodissociation and reaction with $\mathrm{O}\left({ }^{1} \mathrm{D}\right)$, oxygen atoms in an excited singlet state. Satellite observations of episodic $\mathrm{N}_{2} \mathrm{O}$ enhancements in the polar mesosphere (Funke et al., 2008) also suggest the presence of a minor mesospheric source. Nevertheless, from a stratospheric perspective, air masses with low $\mathrm{N}_{2} \mathrm{O}$ mixing ratio generally originate from high altitude, i.e., in the mid to upper stratosphere or mesosphere. Air masses originally coming from the upper stratosphere and further above subside over the course of the winter within the Arctic polar vortex. This is indicated at a given altitude by $\mathrm{N}_{2} \mathrm{O}$ mixing ratios substantially decreasing with time (Greenblatt et al., 2002a). This process is also verified and quantified by numerical studies (Prather and Rodriguez, 1988; Fisher et al., 1993; Plumb et al., 2002). Enhanced mixing ratios of carbon monoxide and molecular hydrogen coinciding with low values of $\mathrm{SF}_{6}$ (Engel et al., 2006) indicate particularly strong downwelling of air even from the mesosphere dur- 
ing the 2003 EUPLEX winter (January through March, cf. Sect. 3).

Due to the strong subsidence and dynamical isolation of air inside the vortex, $\mathrm{N}_{2} \mathrm{O}$ and other long-lived tracers exhibit sharp meridional gradients at the vortex edge. Greenblatt et al. (2002b) demonstrated that the inner edge of the Arctic vortex can be accurately determined by the excess of measured $\mathrm{N}_{2} \mathrm{O}_{\text {meas }}$ relative to characteristic values inside the vortex at a given potential temperature and at a given time, i.e., $\Delta \mathrm{N}_{2} \mathrm{O}=\mathrm{N}_{2} \mathrm{O}_{\text {meas }}-\mathrm{N}_{2} \mathrm{O}_{\text {vortex }}(\Theta)$. At levels around $450 \mathrm{~K}$ that study (Greenblatt et al., 2002b) found a $\Delta \mathrm{N}_{2} \mathrm{O}$ value of $\sim 20 \mathrm{nmol} \mathrm{mol}^{-1}$ to generally correspond well to the dynamical Nash criterion (Nash et al., 1996), which is a commonly used criterion for defining the vortex edge. Extending this concept, we here define what we denote as the $\Delta \mathrm{N}_{2} \mathrm{O}$ vortex index $\left(\xi_{\mathrm{vi}}\right)$ as

$\xi_{\text {vi }}=1-\frac{\Delta \mathrm{N}_{2} \mathrm{O}(\Theta)}{\mathrm{N}_{2} \mathrm{O}_{\text {midlat }}(\Theta)-\mathrm{N}_{2} \mathrm{O}_{\text {vortex }}(\Theta)}$.

Essentially, the $\mathrm{N}_{2} \mathrm{O}$ mixing ratios are linearly rescaled to altitude-independent characteristic index values of $\xi_{\mathrm{vi}}=1$ inside the vortex, and $\xi_{\mathrm{vi}}=0$ at midlatitudes. The parameterization of $\mathrm{N}_{2} \mathrm{O}_{\text {midlat }}(\Theta)$ as used here is based on further measurements with HAGAR at midlatitudes. The vortex index will be introduced and evaluated in detail in a further study (Hösen et al., 2014), which will also demonstrate that $\xi_{\mathrm{vi}}$ can, with some caveats, be viewed as an empirical proxy for the fraction of vortex air in an observed air mass.

As the vortex index is conserved on time scales of isentropic transport, it essentially provides information on whether a measured air mass originally came from the interior of the vortex or from the outside. Therefore, the COPAS measurements can be categorized with respect to their recent origin by means of the index $\xi_{\mathrm{vi}}$. The theoretically maximum value of $\xi_{\mathrm{vi}}$ is one, indicative of pristine vortex air mass. The criterion limits defined for this study to classify the COPAS measurements for $\Theta$-levels above $400 \mathrm{~K}$ are

1. $\xi_{\mathrm{vi}}>0.75$ : sample air originating primarily from the vortex interior

2. $0.75<\xi_{\mathrm{vi}}<0.25$ : sample air with extra-vortex, midlatitude air contributions which are too large for unambiguous apportioning

3. $\xi_{\mathrm{vi}}<0.25$ : sample air originating from well outside of the polar vortex consisting mostly of midlatitude air.

Since the $\xi_{\text {vi }}$ range between 0.4 and 0.8 is populated by relatively few air samples mostly originating from the vortex edge region, the resulting selection of vortex and extra-vortex data mainly needed in this study (i.e., categories 1 and 3) is fairly insensitive to the exact choice of the criterion limits.

The COPAS measurements are recorded with $1 \mathrm{~Hz}$ temporal resolution. One single $\mathrm{N}_{2} \mathrm{O}$ data point is measured by HAGAR only once every $90 \mathrm{~s}$, representative for the air sampled during 2-3s. Consequently, the vortex index $\xi_{\mathrm{vi}}$ has the same temporal resolution. Each $\xi_{\text {vi }}$ value is associated with five COPAS readings, extending from $2 \mathrm{~s}$ before the HAGAR measurement point to $2 \mathrm{~s}$ after. This approach compensates a possible offset of about $1 \mathrm{~s}$ between the controller clocks of COPAS and HAGAR. Those COPAS measurements that are not attributable to a value of $\mathrm{N}_{2} \mathrm{O}$ mixing ratio or vortex index are excluded from the analysis. The results of the COPAS measurements from EUPLEX (2003, cf. Sect. 3) were already discussed in detail by Curtius et al. (2005). However, that study apportioned the data records to the vortex interior or exterior by means of the chemistry transport model CLaMS (see also Sect. 2.4). The results from 2003 discussed here are re-calculated adopting the empirical measure of $\xi_{\mathrm{vi}}$ based on in situ observations during EUPLEX. Consequently, the analysis of EUPLEX data here is based on a different approach, though the conclusions from this recalculation do not differ from the interpretation of Curtius et al. (2005).

\subsection{Meteorological measurements}

Ambient air temperature and static pressure were measured with the Thermo Dynamic Complex (TDC) probe with $1 \mathrm{~Hz}$ resolution and an accuracy of $0.5 \mathrm{~K}$ (Shur et al., 2007). If TDC data were not available (e.g., throughout ESSenCe, cf. Sect. 3) temperature and pressure data were adopted from the Unit for Connection with the Scientific Equipment (UCSE, Sokolov and Lepuchov, 1998), a part of the navigational system of the M-55 Geophysica. UCSE data are provided as $1 \mathrm{~Hz}$ resolved ambient pressure (with an accuracy of \pm $1 \mathrm{hPa}$ ) and temperature ( $\pm 2 \mathrm{~K}$ accuracy).

\subsection{CLaMS modeling}

Model simulations with a 3-dimensional chemistry transport model (CLaMS) (McKenna et al., 2002a, b; Konopka et al., 2007; Grooß et al., 2014) were performed with extensive stratospheric chemistry, including heterogeneous chemistry and particle sedimentation, driven by ERA-Interim reanalysis data (Dee et al., 2011) for the EUPLEX, RECONCILE and ESSenCe campaigns (cf. Sect. 3). For all simulations a suite of inert artificial tracers was utilized, which mark particular regions in the atmosphere (e.g., vortex air and midlatitude air according to the Nash criterion) at the beginning of each simulation. The advection and mixing of the marked air parcels is then modeled by the CLaMS transport scheme, which allows the tracking of the air mass and the detection of its origin (Günther et al., 2008) covering the Northern Hemisphere. For EUPLEX and RECONCILE, the CLaMS simulations were conducted with a horizontal resolution of approximately $70 \mathrm{~km}$ and a maximum vertical resolution of about $400 \mathrm{~m}$ around the tropopause. The simulations were initialized at the beginning of the winter, usually on 1 December, using satellite measurements and tracer-tracer correlations following Grooß et al. (2014). For ESSenCe, the 
CLaMS simulations were initialized on 1 November 2011 and yielded a horizontal resolution of $100 \mathrm{~km}$. For our study an analysis of the tracer distributions led to the determination of the horizontal vortex cross section area (VCSA) averaged for the respective campaign. The VCSAs were calculated within the altitude range that was covered by the in situ measurements, i.e., between 400 and $500 \mathrm{~K}$ of potential temperature. For this altitude range the VCSA is obtained by means of CLaMS calculations in $\Theta$-steps of $10 \mathrm{~K}$ as a mean value $\pm 5 \mathrm{~K}$. The calculated VCSAs exclude any air recently intruded from midlatitudes for which the selected observations would not be representative.

\subsection{Total mass of refractory aerosol matter}

The total refractory aerosol mass within the investigated altitude range $(400 \mathrm{~K}<\Theta<500 \mathrm{~K})$ inside the vortex is estimated in principle by (a) subdividing the vortex column into 10 layers, each of $\Delta \Theta=10 \mathrm{~K}$ thickness; (b) calculating the total mass of the refractory aerosol from the measured $N_{10} \mathrm{nv}$ as a function of $\Theta$ inside each VCSA-layer, assuming certain particle number size distributions which are converted into volume/mass distributions; and (c) adding up the aerosol masses of all layers. In more detail, our estimates are based on parameterizations of the in situ measurements (cf. Sect. 6) and on the following assumptions:

1. Inside the vortex the refractory aerosol mixing ratio that is parameterized as a function of $\Theta$ is assumed to be constant across the surface of each VCSA level. Furthermore, the values are assumed to be time-invariant during the relatively short campaign periods of 3-4 weeks.

2. The size distribution of the refractory aerosol material is assumed to be constant. Furthermore, the size distribution is expected to be within a range that has (a) as uppermost limit: three different parameterizations of the stratospheric background aerosol (Jaenicke, 1980; Wang et al., 1989; Deshler, 2008), and (b) as lowermost limit: the numerically modeled size distribution of MSPs that have reached $30 \mathrm{~km}$ altitude over the winter pole (Bardeen et al., 2008) (cf. Fig. 1). The integrals over the respective model size distributions are scaled as such that they represent the absolute values of observed $N_{10}$ nv. Note that an individual stratospheric sulfuric acid particle may incorporate more than one refractory core. The COPAS technique does not unambiguously allow for assorting an individual refractory residual to a single sulfuric acid droplet. It also does not allow for a strict conclusion as to whether multiple refractory incorporations adhere together after the volatile aerosol compounds are vaporized due to the heated $\mathrm{CO}$ PAS aerosol line. We assume, however, that after contraction due to the surface tension of each evaporating

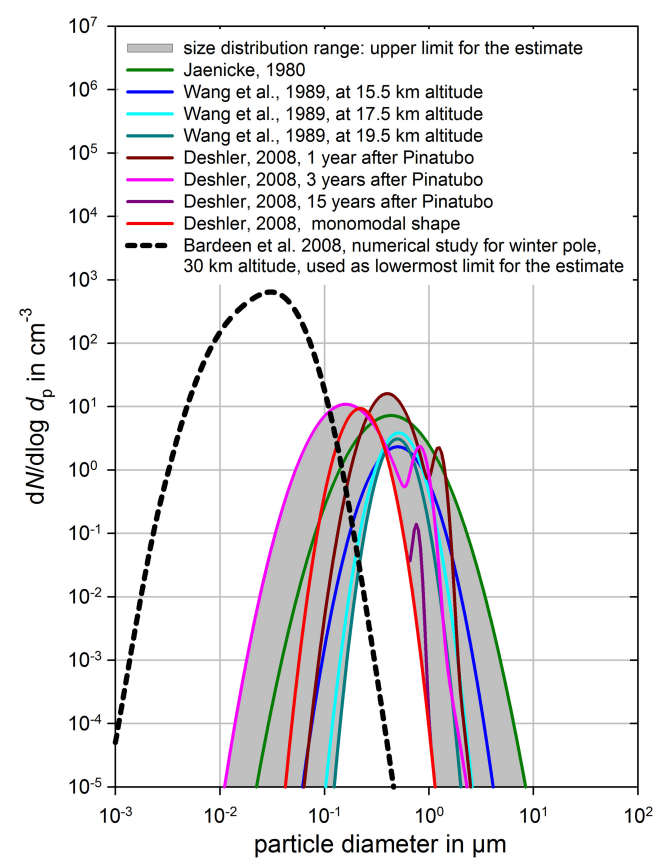

Figure 1. Model size distributions of stratospheric aerosol as provided in parameterized form by different sources: Jaenicke (1980), Wang et al. (1989), and Deshler (2008), and one size distribution published in Bardeen et al. (2008), from numerical simulations of meteoritic material ablated in the mesosphere and subsided to $30 \mathrm{~km}$ altitude. The gray shaded area denotes the range from maximum to minimum values of the size distributions that are used as the upper limit of the estimates described in Sect. 6. The size distribution resulting from numerical investigations serves as the lowermost limit of this estimate.

droplet, the van der Waals forces will keep the remaining refractory residuals in the shape of a single particle.

3. The particle's material density $\rho_{\mathrm{p}}$ is estimated to be on average about $2000 \mathrm{~kg} \mathrm{~m}^{-3}$, with an uncertainty range of $1000-3000 \mathrm{~kg} \mathrm{~m}^{-3}$. The chosen average value is in general agreement with former studies where $\rho_{\mathrm{p}}$ of $2000 \mathrm{~kg} \mathrm{~m}^{-3}$ was used, referring to the density of a typical stone meteorite (Chondrite, e.g., Hunten et al., 1980; Plane, 2004). We use $\rho_{\mathrm{p}}$ of $3000 \mathrm{~kg} \mathrm{~m}^{-3}$ as the uppermost limit as this accounts for the possibility that chemical conversion of meteoritic material dissolved in the $\mathrm{H}_{2} \mathrm{SO}_{4}$ liquid phase produces salts such as iron sulfate hydrates.

4. To estimate the particle burden as a function of model pressure altitude, the relationship between the potential temperature $\Theta$ (in $\mathrm{K}$ ) and the atmospheric pressure $p$ (in $\mathrm{hPa}$ ) is needed, which is derived from parameterizations of the measured values of $\Theta$ and $p$. 


\section{Field campaigns in the years 2003, 2010 and 2011}

Three measurement campaigns were carried out in the Arctic winter seasons of the years 2003, 2010 and 2011, from Kiruna, Northern Sweden $\left(67^{\circ} 49^{\prime} \mathrm{N}, 20^{\circ} 30^{\prime} \mathrm{E}\right)$ deploying the high altitude research aircraft M-55 Geophysica (Stefanutti et al., 1999), which is capable of operating at altitudes of up to $20 \mathrm{~km}$ :

1. EUPLEX, January-March 2003: 15 mission flights

- EUropean Polar stratospheric cloud and Lee wave EXperiment (Günther et al., 2008)

- combined with the European space agency (ESA) ENVISAT - Arctic Validation Campaign

2. RECONCILE, January-March 2010: 13 mission flights

- Reconciliation of essential process parameters for an enhanced predictability of Arctic stratospheric ozone loss and its climate interactions (von Hobe et al., 2013)

- completed by a two-flight mission PremierEX (Spang et al., 2012), and

3. ESSenCe (ESa Sounder Campaign), December 2011: 2 mission flights (Kaufmann et al., 2014).

\subsection{EUPLEX}

The flight activities during EUPLEX/ENVISAT validation (in the following EUPLEX) took place between 10 January through 19 March 2003, with a downtime between 11 and 28 February. Stratospheric air mass exchange between the interior and exterior of the polar vortex during EUPLEX was analyzed by Günther et al. (2008) and further discussed by Werner et al. (2010). In summary, two major vortex breakup events happened during the EUPLEX period: (a) from 21 January through 23 January; and (b) from 15 February to 23 February. Both were followed by vortex recombination (Günther et al., 2008).

\subsection{RECONCILE and PremierEX}

The flight activities during RECONCILE/PremierEX (abbreviated as RECONCILE) were conducted between 17 January and 10 March 2010. During RECONCILE there was a downtime between 2 and 27 February (cf. von Hobe et al., 2013). As described by Dörnbrack et al. (2012), the polar vortex disintegrated into two parts around 15 December 2009, just prior to the RECONCILE flight operations and recombined around 25 December 2009. A second vortex breakup occurred in mid-February followed by recombination in early March. During both breakup events the coldest of the two vortex fragments survived and regenerated. The regeneration period to recover a compact vortex structure lasted until the beginning of January 2010 and the beginning of March 2010, respectively. The simulation of inert artificial tracers in the CLaMS model indicates that the first vortex split in December 2009 caused a strong exchange and dilution of air inside the vortex with air from lower latitudes. In contrast, the second split of the vortex negligibly influenced the air composition inside the vortex. After regeneration at the beginning of March 2010, the air chemical composition inside the vortex exhibited a high grade of homogenization compared to the conditions found following the first split of the vortex in December 2009.

Both missions, EUPLEX and RECONCILE, covered the same seasonal time in the Arctic winter and early spring period. For EUPLEX and RECONCILE the data of the first and second phases, before and after the downtimes, are denoted with suffixes -A and -B.

\subsection{ESSenCe}

The flight activities during ESSenCe were performed during December of 2011, i.e., early in the winter season. In contrast to the more disturbed and warm Arctic winters of 2002/2003 and 2009/2010, the vortex during ESSenCe remained mainly unperturbed. The absence of perturbance led to the early formation of a strong horizontal transport barrier and very cold temperatures below $192 \mathrm{~K}$ at the $50 \mathrm{hPa}$ pressure level in December 2011. During the ESSenCe winter extended fields of persisting synoptic scale PSCs were observed and probed (Molleker et al., 2014; Woiwode et al., 2014).

\section{Observations and results}

The measured aerosol mixing ratios in the Arctic winter stratosphere are summarized in Figs. 2 through 4.

\subsection{EUPLEX winter 2003}

Outside the polar vortex $\left(\xi_{\mathrm{vi}}<0.25\right)$ : for $\Theta>400 \mathrm{~K}$, the mixing ratio $N_{10}$ remains fairly variable between 150 and $300 \mathrm{mg}^{-1}$ and becomes more compact with increasing $\Theta$ until $440 \mathrm{~K}$ with $\sim 200 \mathrm{mg}^{-1}$ (Fig. $2 \mathrm{a}$ and d). The fraction $f$ of non-volatile particles (Fig. $2 \mathrm{c}$ and $\mathrm{f}$ ) for EUPLEX generally remains below $50 \%$.

Variable mixing states of vortex air with midlatitude air $\left(0.25<\xi_{\mathrm{vi}}<0.75\right): N_{10}$ is usually constrained to lower values between 100 and $200 \mathrm{mg}^{-1}$ (Fig. 2a and d). For variable mixing stages the values of $f$ range between 25 and $60 \%$ (Fig. 2c and f).

Inside the vortex $\left(\xi_{\mathrm{vi}}>0.75\right): N_{10}$ continuously increases with $\Theta$. This is particularly obvious in Fig. 2a (also in Fig. 2d, though vertically limited to $465 \mathrm{~K}$ ) from the vertical profile of $N_{10}$ for EUPLEX. The mixing ratio of non-volatile particles $N_{10}$ nv behaves similarly as a function of altitude (Fig. $2 \mathrm{~b}$ and e). Inside the polar vortex $N_{10} \mathrm{nv}$ increases considerably with rising $\Theta$, and significantly exceeds the magnitude of $N_{10}$ nv observed outside the vortex. The fraction $f$ 


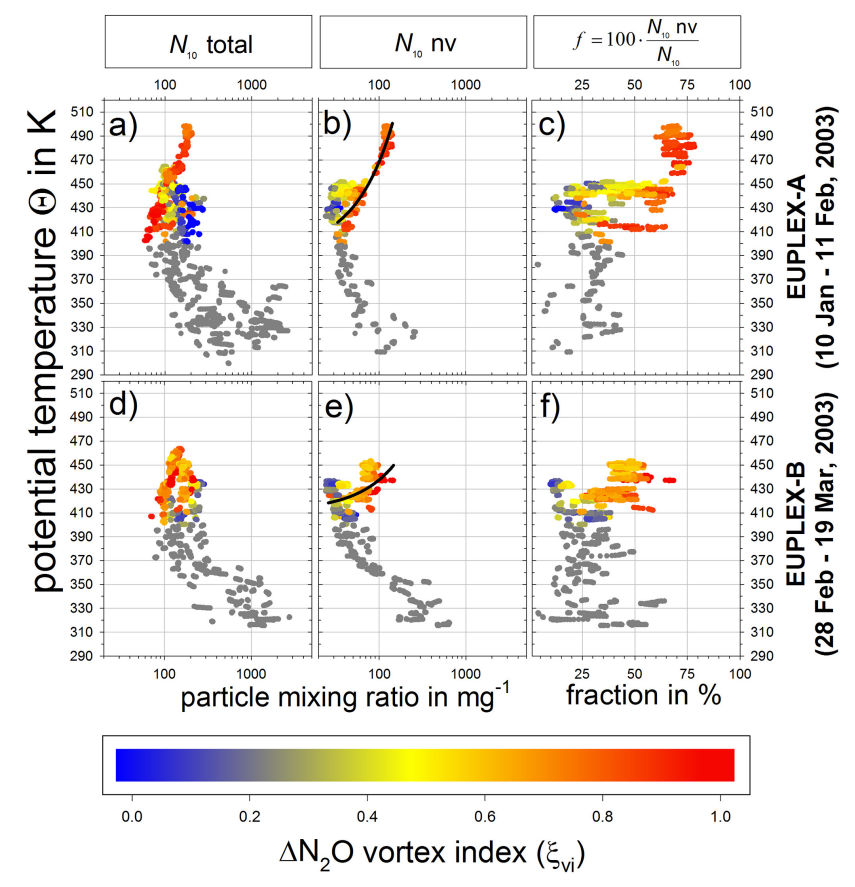

Figure 2. Vertical distribution of particle mixing ratio $N_{10}$ (left column), $N_{10}$ nv (mid column) and resulting fraction $f$ of non-volatile particles (right column) versus the potential temperature $\Theta$ for the EUPLEX campaign in 2003. Data are additionally subdivided (cf. Sect. 3) in period A (January-February 2003) and period B (February-March 2003). Data points for $\Theta$ above $400 \mathrm{~K}$ are color-coded according to $\Delta \mathrm{N}_{2} \mathrm{O}$ vortex index $\xi_{\mathrm{vi}}$. For $\Theta$ below $400 \mathrm{~K}$, data points are left in gray as inside or outside vortex apportioning is not unambiguous (cf. Sect. 2). Black lines indicate a regression over those data points which fulfill the inside-vortex criterion (Sect. 2).

is generally larger than $50 \%$ and reaches up to $80 \%$ during EUPLEX-A (Fig. 2c).

For EUPLEX-B (Fig. 2d) the vertical dependence of $N_{10}$ in principle behaves similarly to the EUPLEX-A period. However, despite the fact that the M-55 Geophysica operated at its maximum ceiling, the high $\Theta$-levels of EUPLEXA could not be reached during EUPLEX-B. Nevertheless, $N_{10}$ nv from Fig. 2e resembles the observations of EUPLEXA. While differences in $f$ between the inside and the outside of the vortex are visible in both data sets, the highest values of up to $80 \%$ were measured during EUPLEX-A.

\subsection{RECONCILE winter 2010}

Outside the polar vortex $\left(\xi_{\mathrm{vi}}<0.25\right)$ : during RECONCILEA $N_{10}$ does not significantly differ between the inside and the outside of the vortex (Fig. 3a). In RECONCILE$\mathrm{B}$, the measurements were mainly made outside the polar vortex with the highest $\Theta$-levels above $510 \mathrm{~K}$. Here $N_{10}$ (Fig. 3d) shows a nearly constant profile with values at about $100 \mathrm{mg}^{-1}$ for $\Theta>400 \mathrm{~K}$. The fraction $f$ of non-volatile particles (Fig. 3c) for RECONCILE-A generally remains below

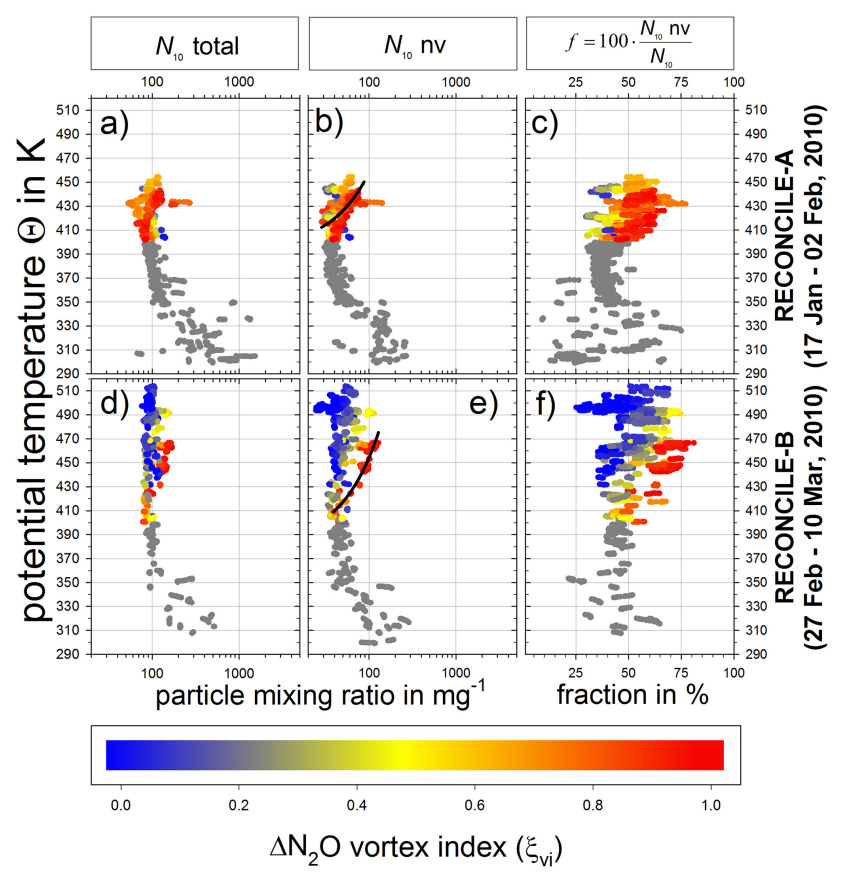

Figure 3. Structured as Fig. 2 for the RECONCILE campaign in 2010 with a subdivision of the mission periods like for EUPLEX. Data are color-coded according to the $\Delta \mathrm{N}_{2} \mathrm{O}$ vortex index $\xi_{\mathrm{vi}}$. For $\Theta$ below $400 \mathrm{~K}$, data points are left in gray as the inside or outside vortex apportioning is not unambiguous (cf. Sect. 2). Black lines indicate a regression of data points that meet the inside-vortex criterion (Sect. 2).

$50 \%$. At altitudes above $450 \mathrm{~K}$, which were reached only in RECONCILE-B, the fraction $f$ exceeds $50 \%$ (Fig. 3f) with significantly enhanced variability until highest flight levels.

Inside the vortex ( $\left.\xi_{\mathrm{vi}}>0.75\right)$ : the vertical profile of $N_{10} \mathrm{nv}$ (Fig. $3 \mathrm{~b}$ and e) indicates that the mixing ratio of refractory aerosol increases inside the vortex where also the highest values of the fraction $f$ (Fig. 3c and f) are reached. During RECONCILE-A the inside and outside vortex distributions are clearly less distinct compared to EUPLEX. This lack of contrast could be due to significant dilution of the vortex content with midlatitude air associated with the vortex breakup and recombination prior to RECONCILE-A. Only a few measurements could be performed well inside the polar vortex during RECONCILE-B. These show in contrast to RECONCILE-A a considerable increase in $N_{10} \mathrm{nv}$ from about $80 \mathrm{mg}^{-1}$ to nearly $180 \mathrm{mg}^{-1}$ between 400 and $460 \mathrm{~K}$ (Fig. 3b).

\subsection{ESSenCe winter 2011}

Outside the polar vortex $\left(\xi_{\mathrm{vi}}<0.25\right)$ : compared to EUPLEX and RECONCILE, the particle mixing ratios measured during ESSenCe in December 2011 are generally low (Fig. 4a) with values of $N_{10}$ smaller than $100 \mathrm{mg}^{-1}$ for $\Theta>400 \mathrm{~K}$. Repeatedly, as also observed during EUPLEX 


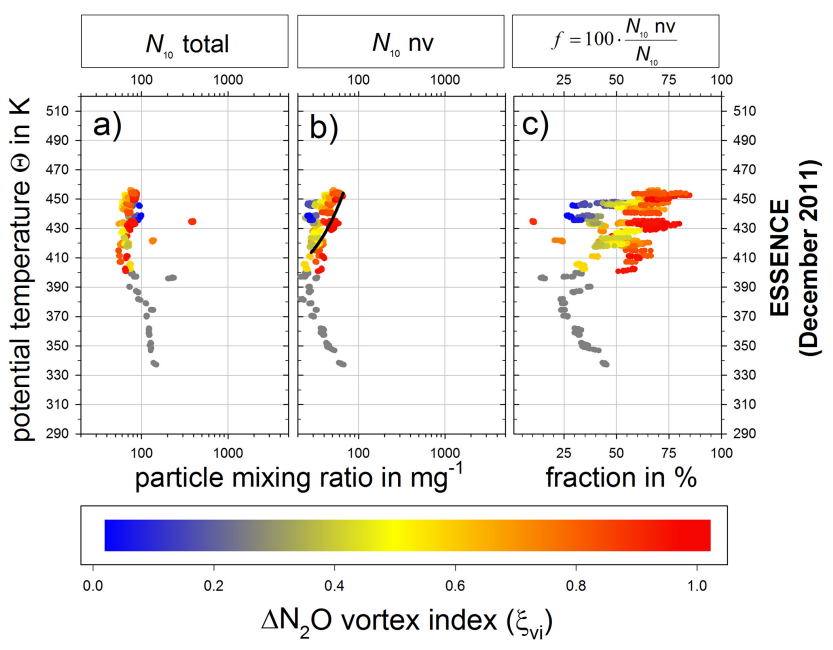

Figure 4. Structured as Figs. 2 and 3 for the ESSenCe campaign in 2011 with the color-coding of data according to the $\Delta \mathrm{N}_{2} \mathrm{O}$ vortex index $\xi_{\text {vi }}$. For $\Theta$ below $400 \mathrm{~K}$, data points are left in gray as inside or outside vortex air cannot be apportioned unambiguously (cf. Sect. 2). Black lines indicate a regression of data points that fulfill the inside-vortex criterion (Sect. 2).

and RECONCILE-B, the fraction $f$ remains below $50 \%$ (Fig. 4c).

Inside the vortex $\left(\xi_{\mathrm{vi}}>0.75\right)$ : the vertical profile of $N_{10} \mathrm{nv}$ (Fig. 4b) exhibits a steeper increase with altitude than $N_{10}$ which agrees qualitatively with the corresponding results of the previous campaigns. As a consequence, similarly high values of $f$ are found (Fig. 4c). This means that during ESSenCe the highest fractions of $f$ were also observed inside the polar vortex reaching values between 60 and $80 \%$.

\section{Synopsis of observations during individual Arctic winters}

All observed vertical profiles of the submicron particle mixing ratios are compared in Fig. 5 in terms of medians with percentiles:

\subsection{Outside the polar vortex $(\Theta>400 \mathrm{~K})$}

$N_{10}$ : lowest values of $N_{10}$ at all altitudes are reached in the earliest winter period (ESSenCe, Fig. 5a). Later in the winter $N_{10}$ may either remain nearly constant with altitude (RECONCILE, Fig. 5i) or may exhibit variability, reaching an enhancement by a factor of up to 2.5 during EUPLEX (Fig. 5e). The considerable difference in the vertical distribution of $N_{10}$ between the EUPLEX A- and B-periods (between 430 and $450 \mathrm{~K})$ may be related to an air mass exchange with vortex air during the vortex breakup (Curtius et al., 2005; Werner et al., 2010).

$N_{10}$ nv: values of $N_{10} \mathrm{nv}$ are similar with $30-60 \mathrm{mg}^{-1}$ for all late-winter situations (Fig. $5 \mathrm{f}$ and $\mathrm{j}$ ). In contrast, during early winter, the values are between 20 and $35 \mathrm{mg}^{-1}$, and thus lower (Fig. 5b).

Fraction $f$ : Isentropic air mass exchanged prior to EUPLEX-B is also indicated by the decreased $f$ (Fig. 5h, open red circles) for $\Theta>420 \mathrm{~K}$. In general, values for $f$ of 25-50\% are very similar for ESSenCe (Fig. 5d) and EUPLEX (Fig. 5h). During RECONCILE (Fig. 5l) $f$ is generally higher, reaching $50 \%$ for $\Theta<450 \mathrm{~K}$. Further above $(450 \mathrm{~K}<\Theta<510 \mathrm{~K}) f$ is increasing up to $60 \%$ outside the polar vortex.

However, high $\Theta$-levels $(450 \mathrm{~K}<\Theta<510 \mathrm{~K})$ were only reached outside the vortex during the second winter period of the year 2010 (RECONCILE-B) and comparable data are not available from the other campaigns.

\subsection{Inside the polar vortex $(\Theta>400 \mathrm{~K})$}

$N_{10}$ and $N_{10}$ nv: both mixing ratios exhibit a considerably steeper increase with $\Theta$ than found outside the vortex. Additionally, the gradient of the enhancement of $N_{10} \mathrm{nv}(\Theta)$ is stronger than for $N_{10}(\Theta)$. Differences between the A- and B-phases of EUPLEX and RECONCILE result mainly from the air mass descent within the vortex. Although $N_{10}$ is comparably low during ESSenCe (Fig. 5a), also here the increase of $N_{10} \mathrm{nv}(\Theta)$ (Fig. 5b) is steeper than that of $N_{10}(\Theta)$.

Fraction $f$ : the strongest increase of $f$ with $\Theta$ were observed (a) for EUPLEX-A, RECONCILE-B - with less disturbed vortex conditions for a certain period prior to the observations, and (b) during ESSenCe when the vortex had just developed. Values of $f$ as high as $70 \%$ were found in the vortex at $\Theta \sim 450 \mathrm{~K}$. Only for EUPLEX-A and RECONCILE-B the median values exceed $70 \%$ at higher altitudes $(\sim 470 \mathrm{~K}$ in RECONCILE-B, Fig. 51). In the $\Theta$ range above $480 \mathrm{~K}$ only data from EUPLEX-A indicate a slight decrease of $f$ with increasing potential temperature.

\subsection{Contribution of volatile particles}

With the mixing ratio difference given as $N_{10}-N_{10} \mathrm{nv}$ the contribution of volatile and semi-volatile particles is accounted for. As long as coated non-volatile particles have diameters larger than $10 \mathrm{~nm}$ they are included in $N_{10}$. Once the volatile coating is removed, releasing a residual with $d_{\mathrm{p}}<10 \mathrm{~nm}$, this remnant is not accounted for with $N_{10}$ nv. Therefore, the COPAS measurement technique does not allow for distinguishing between either a fully volatile particle or a semi-volatile particle with a diameter of close to $10 \mathrm{~nm}$. The mixing ratio difference $N_{10}-N_{10}$ nv during ESSenCe (Fig. 5c) decreases for $\Theta>400 \mathrm{~K}$ outside the vortex and remains nearly constant as a function of altitude inside the vortex. For EUPLEX (Fig. 5g) $N_{10}-N_{10}$ nv does not exhibit such a steep increase with altitude inside the vortex as found for $N_{10} \mathrm{nv}$. Surprisingly, for the RECONCILE case (Fig. 5k) very similar values of $N_{10}-N_{10} \mathrm{nv}$ with $\Theta$ are measured inside and outside of the vortex as well as during RECONCILE-A and 


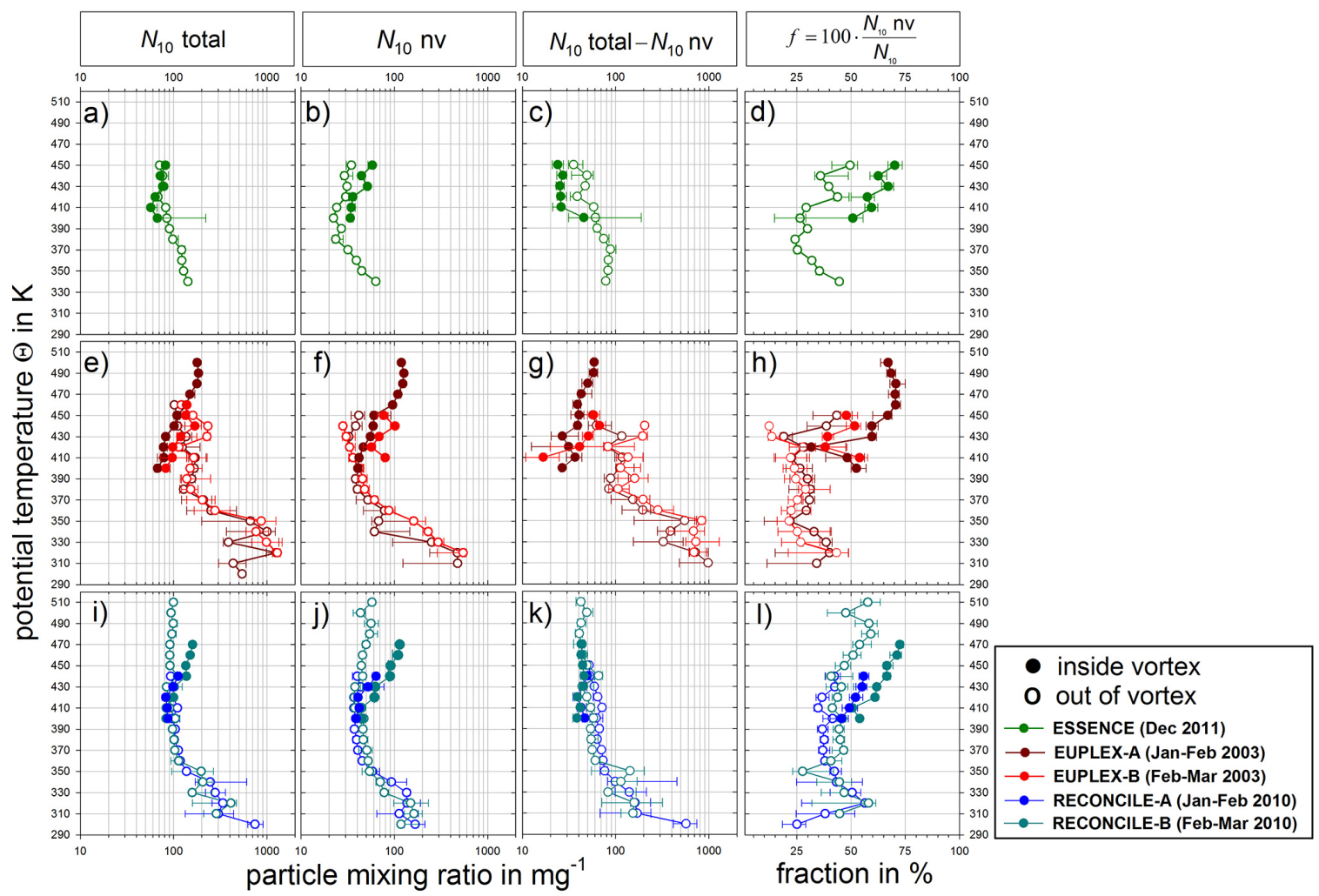

Figure 5. Median vertical profiles of particle mixing ratios with 25th and 75th percentiles (bars) as function of potential temperature $\Theta$. If whiskers are not visible the percentile range is covered by the size of data points. Data are attributed to either originate from inside (dots) or outside the vortex (circles) by using the $\Delta \mathrm{N}_{2} \mathrm{O}$ vortex index $\xi_{\mathrm{vi}}$ (cf. Sect. 2). Aerosol mixing ratios $\mathrm{N}_{10}$, (left column), $\mathrm{N}_{10}$ nv (mid-left column), mixing ratio difference $N_{10}-N_{10}$ nv (mid-right column) and resulting fraction $f$ of refractory particles (right column). (a) to (d) from ESSenCe (i.e., the mission conducted the earliest in the winter season); (e) to (h) data from EUPLEX; (i) to (l) results from RECONCILE.

RECONCILE-B. The most likely reason for this is inherent in the vortex instability. During RECONCILE the vortex was more disturbed and inhomogeneous than during EUPLEX or ESSenCe (cf. Sect. 3).

In summary, increasing particle mixing ratios inside the Arctic vortex are mainly due to refractory aerosols increasing with altitude. The fact that $N_{10}$ nv and $N_{10}-N_{10}$ nv behave differently indicates that $N_{10}$ nv has sources that are decoupled from those of the mainly volatile aerosols. Essentially, the constant values of $N_{10}-N_{10}$ nv observed inside and outside the vortex over the complete RECONCILE mission period may be a result of exceptionally warm stratospheric temperatures. However, for the RECONCILE case this means

a. Increasing particle mixing ratios as a function of altitude inside the vortex are primarily supplied by aerosol containing refractory cores. Otherwise, $N_{10}-N_{10}$ nv would generally show a similar increase with altitude, and

b. Even if $N_{10}-N_{10}$ nv includes non-volatile residuals too small to be detected $\left(d_{\mathrm{p}}<10 \mathrm{~nm}\right)$, the particles descending inside the vortex during RECONCILE con- sisted predominantly of non-volatile particles larger than $10 \mathrm{~nm}$.

\subsection{Particle mixing ratio as function of $\mathrm{N}_{2} \mathrm{O}$ mixing ratio}

In Fig. 6 the particle mixing ratios $N_{10}$ nv and the fractions $f$ are correlated with the mixing ratio of the long-lived tracer $\mathrm{N}_{2} \mathrm{O}$ which was concurrently measured. Since the $\mathrm{N}_{2} \mathrm{O}$ mixing ratios monotonically decrease with rising altitude in the stratosphere, the ordinates in Fig. 6 are reversed.

For high $\mathrm{N}_{2} \mathrm{O}$ mixing ratios $\left(>250 \mathrm{nmol} \mathrm{mol}^{-1}\right)$ positive correlations are found as $\mathrm{N}_{2} \mathrm{O}$ as well as $N_{10}$ nv and $f$ decrease with altitude in the lowermost stratosphere. At smaller $\mathrm{N}_{2} \mathrm{O}$ mixing ratios there is no or only a slight anticorrelation, i.e., increasing $N_{10}$ nv and $f$ with decreasing $\mathrm{N}_{2} \mathrm{O}$ mixing ratios. At values of $\mathrm{N}_{2} \mathrm{O}$ below $200 \mathrm{nmol} \mathrm{mol}^{-1}$ (i.e., at values typical for the Arctic lower stratosphere) a clear anticorrelation is observed showing rising $N_{10}$ nv and $f$ with decreasing $\mathrm{N}_{2} \mathrm{O}$. These low $\mathrm{N}_{2} \mathrm{O}$ values (down to $70 \mathrm{nmol} \mathrm{mol}^{-1}$ ) indicate that air masses from higher altitudes descended inside the vortex. The elevated concentrations of refractory particles 


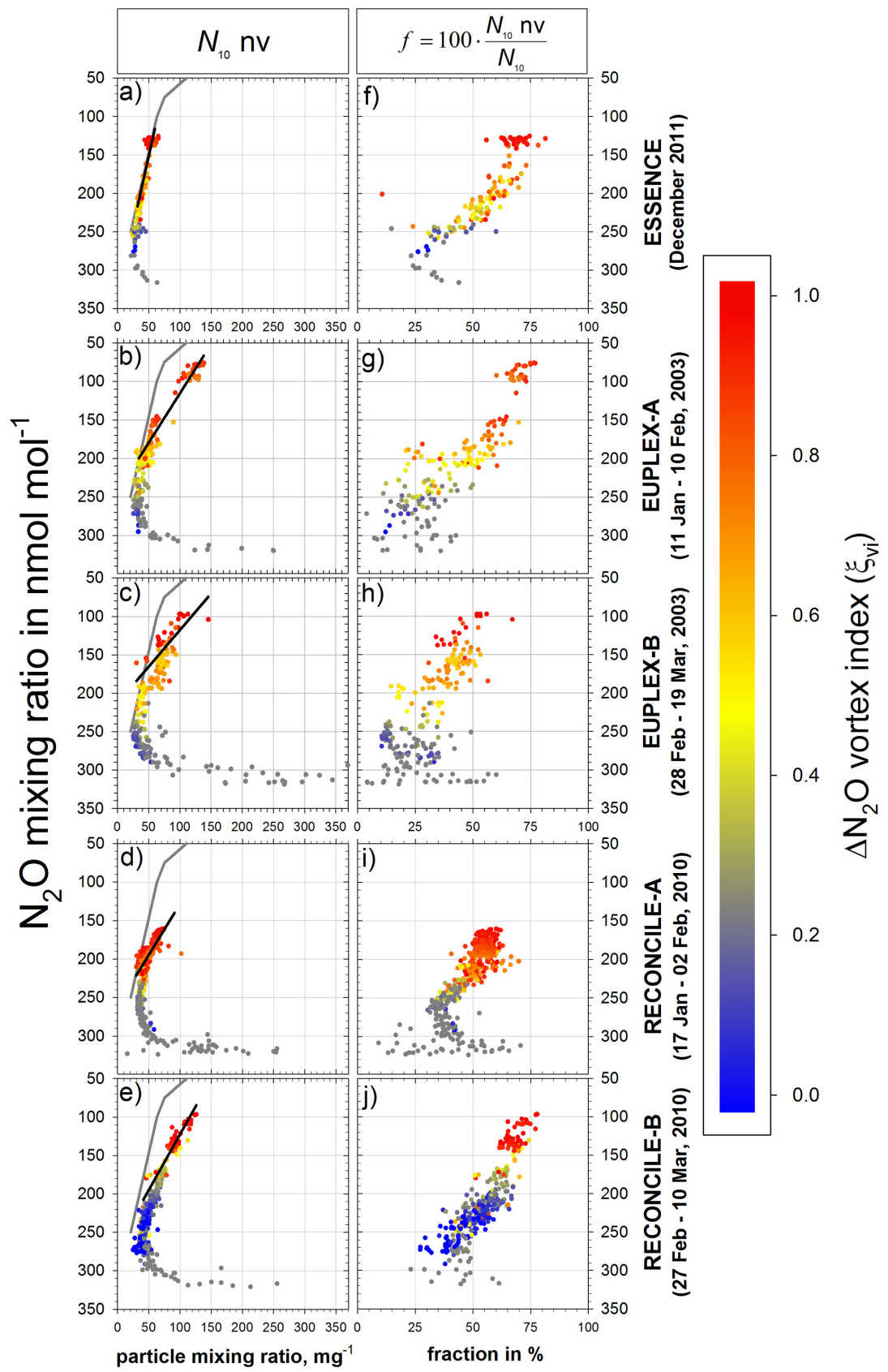

Figure 6. Mixing ratio of non-volatile particles $N_{10} \mathrm{nv}$ and their fractional contribution $f$ to measured total aerosol abundance as function of $\mathrm{N}_{2} \mathrm{O}$ mixing ratio. The data points are colored according to the $\Delta \mathrm{N}_{2} \mathrm{O}$ vortex index $\xi_{\mathrm{vi}}$. Data points are designated in gray if measurements occurred at $\Theta$-levels below $400 \mathrm{~K}$ for which inside or outside vortex apportioning is not unambiguous (cf. Sect. 2). For data measured inside the vortex $\left(\xi_{\mathrm{vi}}>0.75\right)$ the black lines indicate a linear correlation. Alternatively, for $\mathrm{N}_{2} \mathrm{O}$ below $250 \mathrm{nmol} \mathrm{mol}^{-1}$, curves representing a canonical correlation are provided as gray lines with the ESSenCe data (early winter) referring to conditions as closest to the pre-vortex situation (a). The same early winter climatology provides a reference for comparison to data from measurements in progressed winter (b to $\mathbf{e})$.

are thus an indication of such non-volatile materials being supplied from aloft. As this anticorrelation is very similar for the late-winter campaigns of EUPLEX and RECONCILE, its occurrence apparently is not a unique event. Unfortunately for ESSenCe no flights were conducted in the late winter season.

Inside the vortex, the mixing ratio $N_{10} \mathrm{nv}$ generally increases faster than $N_{10}$ with decreasing $\mathrm{N}_{2} \mathrm{O}$. As a consequence, the fraction $f$ of non-volatile particles grows with 
altitude and falling $\mathrm{N}_{2} \mathrm{O}$, and refractory aerosol particles increasingly contribute to the enhanced particle mixing ratios. The ratio $f$ is shown in Fig. $6 \mathrm{f}$ to $6 \mathrm{j}$ as a function of the $\mathrm{N}_{2} \mathrm{O}$ mixing ratio. For $\mathrm{N}_{2} \mathrm{O}$ mixing ratios below $175 \mathrm{nmol} \mathrm{mol}^{-1}$, the fraction of non-volatile aerosol is about $50 \%$, or higher. Further above $f$ increases to values of up to $80 \%$ (EUPLEXA - Fig. 6g, RECONCILE-B - Fig. 6j or ESSenCe - Fig. 6f). Contrary to $N_{10}$ nv the gradients of the fraction $f$ with decreasing $\mathrm{N}_{2} \mathrm{O}$ seem to compare well throughout all cases. This includes the measurements from ESSenCe as well and appears to be independent of the progress of the respective winter season.

In summary, the observations reveal that inside the polar vortex and above $490 \mathrm{~K}$ potential temperature up to $150 \mathrm{mg}^{-1}\left(N_{10} \mathrm{nv}\right)$ from a total of $200 \mathrm{mg}^{-1}\left(N_{10}\right)$ are thermally stable at $250^{\circ} \mathrm{C}$. Therefore, a large fraction of investigated aerosols does not evaporate at $250^{\circ} \mathrm{C}$ and contains materials other than $\mathrm{H}_{2} \mathrm{SO}_{4}, \mathrm{HNO}_{3}, \mathrm{H}_{2} \mathrm{O}$ or other volatile compounds. For these reasons it can be assumed that the thermostable aerosols are predominantly comprised of meteoric ablation materials, although detailed chemical analyses of such particles in the submicron size range are still scarce (cf. Murphy et al., 2013 and references therein).

\section{Implication of the observations and discussion}

\subsection{Vertical profiles of non-volatile particle mixing ratio}

The study of Wilson et al. (1990) already described increasing submicron aerosol concentrations at altitudes of up to $20 \mathrm{~km}$ inside the Arctic vortex by measurements utilizing the NASA ER-2 aircraft during the Airborne Arctic Stratospheric Expedition (AASE) in January and February 1989. Further evidence for an increasing number concentration of condensation nuclei $(\mathrm{CN})$ as a function of altitude was found from balloon-borne measurements with significant excess at higher altitudes (between 20 and $28 \mathrm{~km}$ ) at Kiruna in January 1990 (Hofmann et al., 1990; Fig. 1a therein). However, Wilson et al. (1990) suggested that homogeneous nucleation of the $\mathrm{H}_{2} \mathrm{SO}_{4} / \mathrm{H}_{2} \mathrm{O}$ system may have been the source of these particles in the Arctic winter stratosphere. The observations of Campbell and Deshler (2014) in the Antarctic vortex seem to support this suggestion.

Nevertheless, recent new particle formation was never identified throughout our Arctic measurements as increased concentrations of ultrafine particles (with $6 \mathrm{~nm}<d_{\mathrm{p}}<15 \mathrm{~nm}$ ) were not observed. In addition, the particle mixing ratio difference $N_{10}-N_{10}$ nv (Fig. 5) remains fairly constant with altitude inside and outside the vortex (ESSenCe, Fig. 5c, RECONCILE Fig. 5k). However, if $N_{10}-N_{10}$ nv increases with altitude then $N_{10}$ nv increases more strongly (EUPLEX, Fig. 5f and g) particularly inside the vortex. Thus, it seems apparent that enhanced particle mixing ratios with altitude are mainly linked to a supply of refractory particles from higher altitudes.

Of course, it cannot be ruled out that many refractory residuals were too small (if $d_{\mathrm{p}}<10 \mathrm{~nm}$ ) to be detected with COPAS. Such ultrafine particles are produced by recondensation of metallic vapors from meteoritic ablation to form MSPs (Megner et al. 2008; Saunders et al., 2012; Dohmse et al., 2013). Particles in this size range, for instance if involved in noctilucent cloud formation, could be transported down to the middle stratosphere. Plane (2012) suggests by referring to numerical studies (Bardeen et al., 2008; Megner et al., 2008) that these ultrafine particles most likely agglomerate to diameters of up to $80 \mathrm{~nm}$, e.g., driven by electrical charges, before entering the middle stratosphere from above. It is possible that the observations made by Wilson et al. (1990) also included a major fraction of refractory aerosol material. Under this assumption, and considering the observations by Curtius et al. (2005) from EUPLEX together with our findings presented in this study, we hypothesize that this particle import is a regular feature of the late winter polar vortex in the Northern Hemisphere, provided that the vortex develops throughout the season without being strongly diluted by midlatitude in-mixing.

\subsection{Correlations of non-volatile particles with tracer $\mathrm{N}_{\mathbf{2}} \mathrm{O}$}

As shown in Fig. 6a to 6e, the enhancement of refractory aerosol particles larger than $10 \mathrm{~nm}$ with decreasing $\mathrm{N}_{2} \mathrm{O}$ inside the vortex results in a rather compact anticorrelation. This correlation of $N_{10} \mathrm{nv}$ and $\mathrm{N}_{2} \mathrm{O}$ is indicated by the linear fits for data points with $\xi_{\mathrm{vi}}$ higher than 0.75 . The slope of the correlation is much smaller for the ESSenCe period in December 2011 (Fig. 6a) than for the other cases, and the steepest slopes are found for the EUPLEX-B and RECONCILE-B periods in late winter.

The observed correlations between $N_{10} \mathrm{nv}$ and the longlived tracer $\mathrm{N}_{2} \mathrm{O}$ can be consistently interpreted in terms of the theory of stratospheric tracer-tracer correlations, which is well-developed and verified by observations (cf. Plumb, 2007 , and references therein).

In the absence of the polar vortex, rapid isentropic mixing creates a unique extratropical canonical correlation between two long-lived tracers. The shape of the canonical correlation of tracers is determined by the vertical distribution of the respective sources and sinks. In particular, this canonical correlation is expected to exhibit curvature in the region close to sinks or to sources of either compound, but to be linear elsewhere.

After the formation and ensuing subsidence of the polar vortex, the polar transport barrier isolates the air inside the vortex. As a consequence the correlation within the vortex may change over the course of the winter due to diabatic dispersion within the vortex and/or in-mixing of midlatitude air. For reasons explained by Plumb (2007), the effect of these 
processes is a progressive straightening of the correlations. Thus, while the curved canonical correlation is expected to remain almost unchanged at midlatitudes, the correlation inside the vortex is expected to progressively deviate from the canonical curve toward its concave side due to diabatic dispersion and/or midlatitude in-mixing.

The gray lines in Fig. 6 are congruent with the ESSenCe correlation inside the vortex, qualitatively extrapolated by its expected continuation toward lower $\mathrm{N}_{2} \mathrm{O}$ values. Above the sampled altitudes $\mathrm{N}_{2} \mathrm{O}$ continues to decline and eventually converges towards zero in the mesosphere while $N_{10} \mathrm{nv}$ will further increase by approaching the source region of the refractory aerosol. The observed evolution of the correlations inside the vortex toward higher $N_{10} \mathrm{nv}$ at a given $\mathrm{N}_{2} \mathrm{O}$ from early winter (ESSenCe, Fig. 6a), to mid and late winter (EUPLEX: Fig. 6b or RECONCILE: Fig. 6e) corresponds indeed to a progressive deviation toward the concave side of the original curve as expected according to the arguments of Plumb (2007) described above.

Note that the correlations cannot change due to the mean large-scale subsidence. The correlations could only deviate from their canonical shape due to diabatic dispersion and/or in-mixing from midlatitudes (cf. Plumb, 2007). However, these processes, dispersion or in-mixing, would have different effects on the evolution of the vertical profiles. (1) Midlatitude in-mixing would tend to decrease particle mixing ratios at a given potential temperature above $410 \mathrm{~K}$, thus counteracting the mean subsidence. (2) Alternatively, diabatic dispersion would lead to additional dispersive downward transport of particles. Because of the observed strong particle increase at all potential temperatures above $410 \mathrm{~K}$ between early and late winter (despite slow mean subsidence at these altitudes), we hypothesize the following:

1. The diabatic dispersion is the dominant factor in the evolution of the correlations and likely also contributes significantly to the evolution of the vertical profiles.

2. The diabatic dispersion is thus an important mechanism for the transport of refractory particles to the vortex bottom.

In order to evaluate similarities and differences of the gradient as a function of $\Theta$ and the $\mathrm{N}_{2} \mathrm{O}$ mixing ratio, Fig. 7 shows the corresponding scatter plots. Note that only measurement points from the vortex interior are displayed and that the scale of the color code extends from 0.75 to 1.0 for $\xi_{\mathrm{vi}}$.

\subsubsection{Outflow region at the vortex bottom $(380 \mathrm{~K}<\Theta \leq 410 \mathrm{~K})$}

From the RECONCILE data set shown in Fig. $7 \mathrm{~b}$ and $7 \mathrm{e}$ it can be seen that the functions $N_{10} \mathrm{nv}(\Theta)$ and $N_{10} \mathrm{nv}\left(\mathrm{N}_{2} \mathrm{O}\right)$ are not linear over the entire range of $\Theta$ and $\mathrm{N}_{2} \mathrm{O}$. Instead there is a much smoother increase for $380 \mathrm{~K}<\Theta \leq 410 \mathrm{~K}$

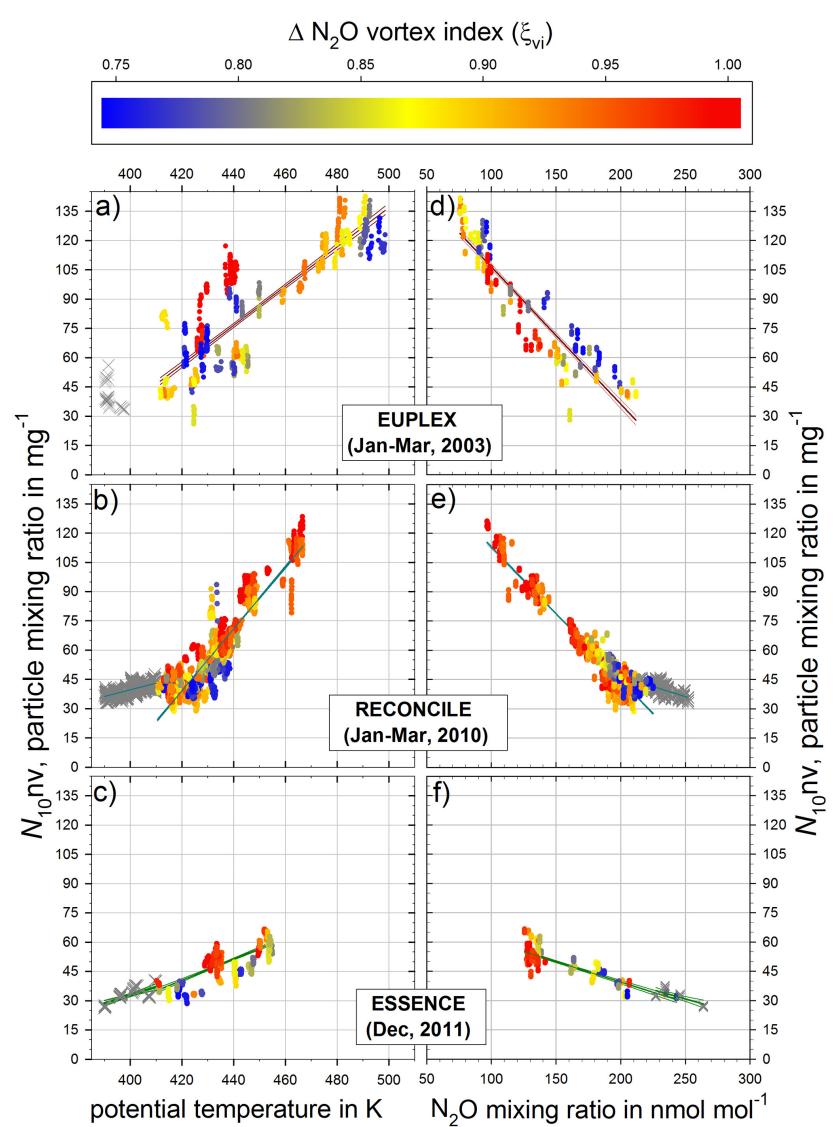

Figure 7. Mixing ratio of non-volatile particles $N_{10}$ nv as a function of potential temperature $\Theta$ (a to c) and as a function of $\mathrm{N}_{2} \mathrm{O}$ mixing ratio ( $\mathbf{d}$ to $\mathbf{f}$ ) for measurements inside the vortex (i.e., where $\Delta \mathrm{N}_{2} \mathrm{O}$ vortex index $\left.\xi_{\mathrm{vi}}>0.75\right)$. Data points are color-coded by means of $\Delta \mathrm{N}_{2} \mathrm{O}$ vortex index in the range $0.75<\xi_{\mathrm{vi}}<1$. Results are separated for $\Theta$-levels below $410 \mathrm{~K}$ (crosses) and above $410 \mathrm{~K}$ (dots) to account for the visible discontinuity (i.e., a transition zone) at the vortex bottom. Linear correlations are assumed for $\Theta$-levels above $410 \mathrm{~K}$ and linear regressions are implied. These are separately displayed in Fig. 8 for better comparability.

compared to $\Theta>410 \mathrm{~K}$. The data points of the altitude range below $410 \mathrm{~K}$ are shown as crosses (Fig. 7b), likewise for the EUPLEX (Fig. 7a) and ESSenCe (Fig. 7c) data. The deviation from a single straight line is most pronounced for RECONCILE. For ESSenCe, there may not have been enough data points or, more likely, the distinct gradients for altitudes above $410 \mathrm{~K}$ had not yet developed during early winter.

The two different correlations of the two altitude bands may arise from the dynamics at the vortex bottom. Below $410 \mathrm{~K}$ (Fig. $7 \mathrm{~b}$ ), the vortex boundary no longer acts as an effective transport barrier, thus allowing for more efficient isentropic exchange and mixing with the midlatitudes (Haynes and Shuckburgh, 2000). As a result, in this region, no separate vortex correlation forms. Observational indications for the existence of such a transition zone were previously described by Weinheimer et al. (1993). For a very sim- 
Table 1. Parameterization with standard error $(\sigma)$ of the linear regression between the particle mixing ratio $N_{10}$ nv with potential temperature $\Theta$ and with $\mathrm{N}_{2} \mathrm{O}$ mixing ratio for different altitude ranges, $\Theta<410 \mathrm{~K}$ and $\Theta>410 \mathrm{~K}$, respectively, within the vortex as displayed in Fig. 8 . $y=f(x)=a x+b$ in $\mathrm{mg}^{-1} ; a_{1}, b_{1}$ and correlation coefficient $r_{1}^{2}$ for $390 \mathrm{~K}<\Theta \leq 410 \mathrm{~K} ; a_{2}, b_{2}$ and correlation coefficient $r_{2}^{2}$ for $\Theta>410 \mathrm{~K}$.

\begin{tabular}{c|ccc|ccc}
\hline & \multicolumn{3}{|c|}{$x=\Theta$ in K } & \multicolumn{3}{c}{$x=\mathrm{N}_{2} \mathrm{O}_{\text {in nmol mol }} \mathrm{nm}^{-1}$} \\
& EUPLEX & RECONCILE & ESSenCe & EUPLEX & RECONCILE & ESSenCe \\
\hline$a_{1} \pm \sigma$ & - & $0.34 \pm 0.02$ & $0.42 \pm 0.06$ & - & $-0.21 \pm 0.02$ & $-0.19 \pm 0.04$ \\
$b_{1} \pm \sigma$ & - & $-96.3 \pm 7.5$ & $-135.6 \pm 24.8$ & - & $88.3 \pm 3.9$ & $77.3 \pm 9.2$ \\
$r_{1}^{2}$ & - & 0.43 & 0.52 & - & 0.45 & 0.58 \\
\hline$a_{2} \pm \sigma$ & $1.01 \pm 0.02$ & $1.56 \pm 0.01$ & $0.54 \pm 0.02$ & $-0.71 \pm 0.05$ & $-0.68 \pm 0.01$ & $-0.21 \pm 0.01$ \\
$b_{2} \pm \sigma$ & $-365.8 \pm 8.9$ & $-616.3 \pm 5.3$ & $-187.9 \pm 9.3$ & $178.5 \pm 2.1$ & $180.9 \pm 1.1$ & $81.4 \pm 1.2$ \\
$r_{2}^{2}$ & 0.74 & 0.83 & 0.54 & 0.85 & 0.90 & 0.72 \\
\hline
\end{tabular}

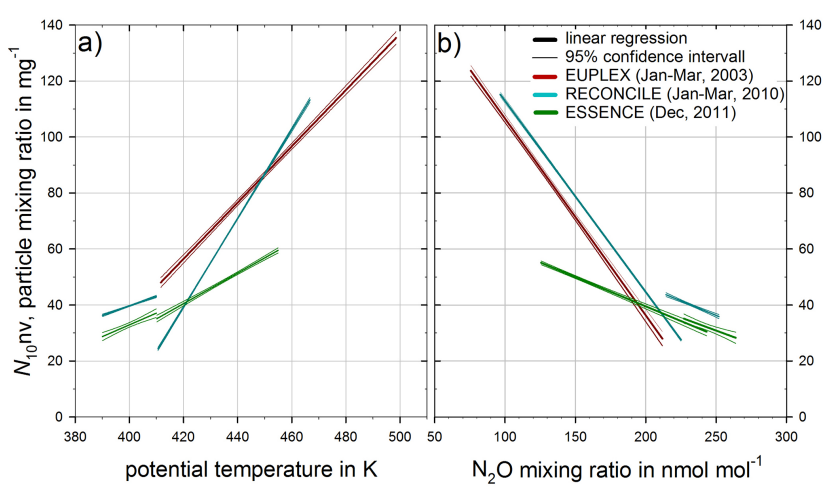

Figure 8. Linear regressions with $95 \%$ confidence interval for the mixing ratio of non-volatile particles $N_{10} \mathrm{nv}$ as function of potential temperature $\Theta$ (a) and $\mathrm{N}_{2} \mathrm{O}$ mixing ratio (b). Results from measurements within the vortex $\left(\Delta \mathrm{N}_{2} \mathrm{O}\right.$ vortex index $\left.\xi_{\mathrm{vi}}>0.75\right)$ are shown for the three Arctic missions: EUPLEX (2003), RECONCILE (2010) and ESSenCe (2011).

ilar $\Theta$-altitude range Borrmann et al. (1995) identified this transition zone below the vortex bottom by linear correlations between ozone and the aerosol surface area mixing ratio, though from larger particles of volcanic origin. The described discontinuity is not only present in the linear correlations between the mixing ratio $N_{10} \mathrm{nv}$ and potential temperature, but also in those between $N_{10}$ nv and $\mathrm{N}_{2} \mathrm{O}$ for RECONCILE (Fig. 7e). This clearly shows that different air masses are involved, and we presume that efficient air mass exchange in the outflow region at the vortex bottom causes the observed discontinuity. A similar although much less pronounced discontinuity is also observed for ESSenCe, while for EUPLEX there are too few observations at the vortex bottom for it to be discerned.

\subsubsection{In the unperturbed vortex $(\Theta>410 \mathrm{~K})$}

The plots in Fig. 7 exhibit linear relationships over most of the observed $\mathrm{N}_{2} \mathrm{O}$ range with correlation coefficients $r^{2}$ of 0.72-0.90 for EUPLEX, RECONCILE and ESSenCe (cf. Ta- ble 1). Over the observed $\Theta$ range the $r^{2}$ of 0.54 for the ESSenCe case indicates comparably weak confidence in a linear relationship between $\Theta$ and $N_{10} \mathrm{nv}$.

All linear regressions of $N_{10} \mathrm{nv}$ versus the potential temperature and the $\mathrm{N}_{2} \mathrm{O}$ mixing ratio from the three field campaigns are shown for comparison in Fig. 8, together with the $95 \%$-confidence intervals. The resulting regression parameters are presented in Table 1.

a. $N_{10} \mathrm{nv}$ as a function of potential temperature (Fig. $8 \mathrm{a}$ ): $N_{10}$ nv $(\Theta)$ strongly depends on the large-scale dynamics of the vortex, in particular on the strength of vortex descent and on the vortex stability over the winter period. The observed vertical gradients of the three campaigns are qualitatively consistent with continuing diabatic descent of vortex air and the surfaces of $N_{10} \mathrm{nv}$. The smallest vertical gradient is observed for ESSenCe (December) and the largest for RECONCILE (dominated by the March observations up to $470 \mathrm{~K}$ ). The corresponding values for EUPLEX (dominated by the January data up to $500 \mathrm{~K}$ ) lie in between.

b. $N_{10}$ nv as a function of the $\mathrm{N}_{2} \mathrm{O}$ mixing ratio (Fig. 8 b): the agreement of the regression slopes between EUPLEX (i.e., $-0.71 \pm 0.05$ ) and RECONCILE (i.e., $-0.68 \pm 0.01)$ is remarkable. Only the absolute values of $N_{10} \mathrm{nv}$ are shifted along the ordinate by a factor of about 1.1. Note that in terms of the covered range of $\mathrm{N}_{2} \mathrm{O}$ mixing ratio, measurements of RECONCILE-B dominate the regression compared to the RECONCILEA period (cf. Fig. 6a to 6e together with Fig. 7d to f). Thus, the data from the later mission period assume more weight in the regression calculation. Such a weighting imbalance is less pronounced for the EUPLEX period, although the lowest $\mathrm{N}_{2} \mathrm{O}$ mixing ratios were detected predominantly during the earlier EUPLEX period. Finally, the slopes and intercepts of the ESSenCe data regressions are quite different from those of the other missions.

In summary, the observed correlations are qualitatively consistent with the expected development of the $N_{10} \mathrm{nv}-\mathrm{N}_{2} \mathrm{O}$ 
correlation inside the vortex over the course of the winter (as outlined above). Starting from the original canonical midlatitude correlation at the time the vortex forms, inside the isolated vortex the mixing ratio $N_{10} \mathrm{nv}$ will continuously increase on a given $\mathrm{N}_{2} \mathrm{O}$ surface: this is consistent with the observed increase of $N_{10}$ nv between ESSenCe (December), EUPLEX (more weighted toward January data) and RECONCILE (dominated by March data) and is most likely driven by diabatic dispersion, in accord with current understanding of polar tracer transport (Plumb et al., 2002; Plumb, 2007).

\subsection{Implications for PSC formation}

The import of refractory material into the vortex constitutes an important source of particles for a region where the isolation of the vortex from isentropic in-mixing promotes heterogeneous chemical reactions connected to ozone depletion. The non-volatile particles carried from aloft are most likely incorporated by stratospheric sulfate aerosol or covered with sulfuric acid and provide surfaces for condensable materials and heterogeneous chemical reactions (Peter, 1997; Wegner et al., 2012). PSC formation is usually thought to occur by heterogeneous nucleation on the homogeneously nucleated $\mathrm{H}_{2} \mathrm{SO}_{4}-\mathrm{H}_{2} \mathrm{O}$ droplets of the stratospheric background aerosol. It may be assumed that stratospheric cloud elements also, or even preferably, form on preexisting condensation surfaces (Hoyle et al., 2013; Engel et al., 2013) as provided by refractory particles, particularly at times when stratospheric background aerosol concentrations are low. In particular, this process may be relevant in the polar stratosphere with a low degree of $\mathrm{HNO}_{3}$ supersaturation (Voigt et al., 2005), which is a frequently occurring condition in the Arctic.

Based on our data, up to $75 \%$ by number of the aerosol particles inside the vortex are, or contain, refractory cores with a diameter larger than $10 \mathrm{~nm}$. Their presence contributes to the probability that PSC elements can form, either directly, if the refractory cores have uncoated or partially coated surfaces, or indirectly, if the cores are fully incorporated in a droplet of condensable material. A measure of the grade of coating of each refractory aerosol is not obtainable with the COPAS technique. The ability of an uncoated or partially coated refractory aerosol particle to act as a PSC condensation nucleus may strongly depend on the chemical composition and surface property of the individual particle. Incorporated in a droplet, the ability of acting as a PSC condensation nucleus should not differ from that of a pure, e.g., $\mathrm{H}_{2} \mathrm{SO}_{4}$ droplet if the core is inert and insoluble. If, in contrast, parts of the refractory core are dissolved, important chemical conversion or electric charges and polarity may influence the ability of such a solution droplet to support PSC formation.

In conclusion, the refractory particles support the availability of condensation surfaces, and therefore the probability that stratospheric cloud particles form only homogeneously is diminished. Of course, our measurements cannot exclude that PSCs form via new particle formation at even higher altitudes than explored by our mission flights. However, above an altitude of $27 \mathrm{~km}$ the ambient temperature becomes too high (>195 K ambient temperature) and the vapor saturation too low for new particle formation of PSC elements to occur.

\subsection{Estimates of the refractory aerosol mass contained in the vortex}

\subsubsection{Calculation steps}

In order to estimate the total amount of refractory submicron aerosol contained inside the Arctic vortex, the following steps were taken:

1. The vortex cross sectional areas (VCSAs) are calculated by means of the CLaMS model in potential temperature bins of $10 \mathrm{~K}$. For the $\Theta$ range of $400-500 \mathrm{~K}$, the VCSAs are averaged over the respective campaign duration (cf. Sect. 2, results in Table 3). The determined VCSAs include the horizontally almost homogeneous parts of the vortex for which the selected observations with values of $\xi_{\mathrm{vi}}$ higher than 0.75 are representative. Thus, air recently intruding from midlatitudes is not included.

2. Based on the regressions shown in Fig. 8a, the mixing ratios $N_{10} \mathrm{nv}$ are parameterized as a function of the potential temperature (Table 1).

3. The available stratospheric aerosol size distributions are parameterized as a sum of lognormal distribution functions, where they are not already given in that form in literature. From these lognormal distributions, applying the Hatch-Choate equations (Hinds, 1999), the diameter of average volume and the total volume concentration are calculated. From the total volume and total number concentrations, the average volume per particle $v_{\mathrm{p}}$ is computed.

a. As a lowermost limit of this estimate the modeled size distribution of meteoritic ablation material at $30 \mathrm{~km}$ altitude above the winter pole is taken (Bardeen et al., 2008 and cf. Fig. 1). For the mean volume per particle $v_{\mathrm{p}}$ this size distribution yields $3.1 \times 10^{-23} \mathrm{~m}^{3}$. The uncertainty with respect to the resulting mean aerosol mass value is mainly given by the range of material densities (cf. Step 7 in this list).

b. As the uppermost limit of this estimate, the parameterized model size distributions of stratospheric aerosol from three different studies (Jaenicke, 1980; Wang et al., 1989; Deshler, 2008) are considered. The volume per particle is given as a volume range (cf. Table 2) resulting from the range of underlying size distributions (Fig. 1). We consider 
Table 2. Estimated volume $\left(v_{\mathrm{p}}\right)$ of one refractory aerosol particle, particulate material density $\left(\rho_{\mathrm{p}}\right)$ and parameterized $\Theta-p$ relationship for the estimate of the total mass of refractory aerosol within the air volume of the polar vortex (cf. Sect. 6).

\begin{tabular}{|c|c|c|c|c|c|c|c|c|c|c|c|}
\hline & \multirow[b]{3}{*}{$v_{\mathrm{p}}$ in $\mathrm{m}^{3}$} & \multirow[b]{3}{*}{$\rho_{\mathrm{p}}$ in $\mathrm{kg} \mathrm{m}^{-3}$} & \multicolumn{9}{|c|}{$p$ in $\mathrm{hPa}=\mathrm{A}+\exp (-\mathrm{C} \cdot(\Theta$ in $\mathrm{K}-\mathrm{B}))$} \\
\hline & & & \multicolumn{3}{|c|}{ EUPLEX } & \multicolumn{3}{|c|}{ RECONCILE } & \multicolumn{3}{|c|}{ ESSenCe } \\
\hline & & & A & B & $\mathrm{C}$ & A & B & $\mathrm{C}$ & A & $\mathrm{B}$ & $\mathrm{C}$ \\
\hline Mean & $5.00 \times 10^{-20}$ & 2000 & 46.1 & 550.5 & 0.0252 & 39.3 & 698.6 & 0.0149 & 46.0 & 557.6 & 0.0246 \\
\hline Min. & $8.71 \times 10^{-21}$ & 1000 & 31.8 & 594.7 & 0.0198 & 34.3 & 743.4 & 0.0125 & 38.8 & 592.3 & 0.0203 \\
\hline Max. & $1.86 \times 10^{-19}$ & 3000 & 30.8 & 753.8 & 0.0127 & 25.1 & 832.7 & 0.0110 & 4.87 & 823.0 & 0.0109 \\
\hline
\end{tabular}

the uncertainty as the maximum range of average volumes per particle derived from these size distributions available in literature.

4. The total particle volume per air mass (in $\mathrm{m}^{3} \mathrm{~kg}^{-1}$ ) is calculated from $N_{10} \mathrm{nv}$ and the average volume per particle from Step 3 as a function of the potential temperature.

5. The $\Theta-p$ relationship is parameterized based on measurements for the respective Arctic campaign (Table 2). For each campaign the uncertainty is considered as the maximum range of all measured relationships. The total air mass is then calculated from the VCSA values from Step 1 and the pressure differences at chosen $\Theta$-levels, which have a distance of $10 \mathrm{~K}$ from each other.

6. The total particle volume per $\Theta$-level is calculated from the total air mass per $\Theta$-level and the particle volume ratio (in $\mathrm{m}^{2} \mathrm{~kg}^{-1}$ ) for the corresponding level.

7. The total particle mass per $\Theta$-level is calculated from the total particle volume and the particle density. We consider the uncertainty of the particle density as the range between unit density $\left(\rho_{\mathrm{p}}=1000 \mathrm{~kg} \mathrm{~m}^{-3}\right)$ and the density of solid meteoritic material. To account for chemical conversion of meteoritic material, e.g., into salts, a material density $\rho_{\mathrm{p}}$ of $3000 \mathrm{~kg} \mathrm{~m}^{-3}$ is chosen as the uppermost limit (cf. Table 2). This relatively high value of $\rho_{\mathrm{p}}$ is justified by the maximum material density reached by iron sulfate hydrates, a possible remnant of dissolved meteoritic material in $\mathrm{H}_{2} \mathrm{SO}_{4}$. For the estimate $\rho_{\mathrm{p}}=2000 \mathrm{~kg} \mathrm{~m}^{-3}$ is chosen as the mean value of the material densities range. The total particle mass is obtained as the sum of all $\Theta$-levels between 400 and $500 \mathrm{~K}$ (Table 3) for which particle data were available.

Of course there are considerable uncertainties inherent in such estimates:

a. About a factor of 5 in uncertainty is implied in $v_{\mathrm{p}}$ from the range of size distributions. The therein included, but most important uncertainty arises from the unknown true size distribution of refractory particles with diameters between $10 \mathrm{~nm}-1 \mu \mathrm{m}$. COPAS detects the particles of this size range, but does not size them. The use of the stratospheric aerosol size distributions does only provide an uppermost extreme for estimating the meteoric aerosol mass. The knowledge of the volume concentration of volatile in relation to non-volatile aerosol material would significantly reduce the uncertainty our approach is bearing.

b. Further uncertainties of a factor of 1.2 come from the $\Theta-p$ relationship, and an additional uncertainty factor of 1.7 results from the range of particle material densities $\rho_{\mathrm{p}}$.

c. Also, it has to be considered that substantial amounts of refractory aerosol descending in the vortex are not accounted for in our approach. Examples are those particles in the vortex edge region or within and below the vortex bottom transition zone, as well as particles that isentropically escaped from the vortex to midlatitudes prior to the observation period.

d. Due to the COPAS activation limit and the inlet transmission, particles of diameters smaller than $10 \mathrm{~nm}$ and larger than about $1 \mu \mathrm{m}$ are disregarded (Weigel et al., 2009).

e. The model estimates of the VCSAs also involve uncertainties of at the most $50 \%$ as a conservative estimate of this uncertainty, inherent with the accuracy of the computed vortex edge and of the simulation of the mixing parameterization.

\subsubsection{Estimate results}

In Tables 3 and 4 the results of our estimates are provided in terms of the altitude-resolved mass of refractory aerosol as a function of the potential temperature. The values for the uppermost estimate are shown in Table 3 whilst the lowermost estimates are given in Table 4 . In the following mass values are provided with a superscript index ${ }^{(*)}$ for a better traceability of the data's origin.

The applied pressure altitudes for the $\Theta$-levels indicate the various meteorological vortex conditions of the different campaigns. The resulting uppermost estimate (Table 3) 
Table 3. Averaged vortex cross section areas from CLaMS analyses and resulting altitude-resolved refractory aerosol masses. The integrated aerosol masses inside the vortex are estimated from the in situ measurements under the assumptions detailed in Sect. 6. This estimate provides an uppermost limit of refractory aerosol mass as it is based on size distributions of the background stratospheric aerosol parameterized from observations (cf. Sect. 2 and Jaenicke, 1980; Wang et al., 1989; Deshler, 2008). Vertical coordinates are given as potential temperatures and the corresponding pressure ranges from the $\Theta-p$ relationship are provided in Table 2 . By applying specific uncertainty factors $\left(\sqrt{M_{\mathrm{nv}}^{\max } / M_{\mathrm{nv}}^{\min }}\right)$ the extremes of involved uncertainties are covered. Indices ${ }^{(*)}$ simplify the traceability of the data's origin in the text.

\begin{tabular}{|c|c|c|c|c|c|c|c|c|c|}
\hline \multirow[b]{3}{*}{$\Theta$ in $\mathrm{K}$} & \multicolumn{3}{|c|}{ Averaged vortex cross section area in $\mathrm{km}^{2}$} & \multicolumn{6}{|c|}{$\begin{array}{l}\text { Altitude-resolved mass of refractory aerosol } \\
\text { based on size distribution of background stratospheric aerosol }\end{array}$} \\
\hline & EUPLEX & RECONCILE & ESSenCe & \multicolumn{2}{|c|}{ EUPLEX } & \multicolumn{2}{|c|}{ RECONCILE } & \multicolumn{2}{|c|}{ ESSenCe } \\
\hline & & & & $p$ range in $\mathrm{hPa}$ & $M_{\mathrm{nv}}$ in $\mathrm{kg}$ & $p$ range in $\mathrm{hPa}$ & $M_{\mathrm{nv}}$ in $\mathrm{kg}$ & $p$ range in $\mathrm{hPa}$ & $M_{\mathrm{nv}}$ in $\mathrm{kg}$ \\
\hline 400 & - & 12873600 & 6437790 & - & - & $131-119$ & $6.7 \times 10^{6}$ & $101-89$ & $2.5 \times 10^{6}$ \\
\hline 410 & 10259900 & 15007800 & 7474930 & $85-77$ & $4.4 \times 10^{6}$ & $119-108$ & $2.2 \times 10^{6}$ & $89-79$ & $2.4 \times 10^{6}$ \\
\hline 420 & 13184650 & 16898750 & 9309220 & $77-70$ & $5.3 \times 10^{6}$ & $108-98$ & $4.7 \times 10^{6}$ & $79-72$ & $2.7 \times 10^{6}$ \\
\hline 430 & 15466600 & 18565200 & 11463200 & $70-64$ & $5.7 \times 10^{6}$ & $98-90$ & $7.0 \times 10^{6}$ & $72-66$ & $3.0 \times 10^{6}$ \\
\hline 440 & 16893950 & 20123350 & 13472600 & $64-60$ & $5.6 \times 10^{6}$ & $90-83$ & $8.7 \times 10^{6}$ & $66-62$ & $3.1 \times 10^{6}$ \\
\hline 450 & 18023400 & 21159700 & 14218900 & $60-57$ & $5.2 \times 10^{6}$ & $83-77$ & $9.9 \times 10^{6}$ & $62-58$ & $2.8 \times 10^{6}$ \\
\hline 460 & 19140750 & 22579350 & 14915600 & $57-55$ & $4.8 \times 10^{6}$ & $77-72$ & $1.1 \times 10^{7}$ & $58-56$ & $2.5 \times 10^{6}$ \\
\hline 470 & 20157300 & 23282300 & - & $55-53$ & $4.3 \times 10^{6}$ & $72-67$ & $1.1 \times 10^{7}$ & - & - \\
\hline 480 & 21287700 & - & - & $53-51$ & $3.9 \times 10^{6}$ & - & - & - & - \\
\hline 490 & 22248850 & - & - & $51-50$ & $3.4 \times 10^{6}$ & - & - & - & - \\
\hline \multirow[t]{3}{*}{500} & 23147150 & - & - & $50-49$ & $3.0 \times 10^{6}$ & - & - & - & - \\
\hline & & & & \multicolumn{6}{|c|}{ Summed mass of refractory aerosol in $\mathrm{kg}$} \\
\hline & & & $\begin{array}{l}\text { Total sum } \\
\text { Uncertainty factor } \\
\text { Sum }(100-67 \mathrm{hPa}) \\
\text { Uncertainty factor }\end{array}$ & & $\begin{array}{c}\text { (1) } 45.6 \times 10^{6} \\
10.8 \\
15.5 \times 10^{6} \\
9.8\end{array}$ & & $\begin{array}{l}\text { (3) } 61.7 \times 10^{6} \\
9.8 \\
\text { (4) } 48.1 \times 10^{6} \\
\text { (10) } 9.9\end{array}$ & & $\begin{array}{l}\text { (2) } 21.3 \times 10^{6} \\
9.9 \\
\text { (5) } 10.6 \times 10^{6} \\
\text { (11) } 9.2\end{array}$ \\
\hline
\end{tabular}

amounts to a mass of approximately $45.6 \times 10^{6} \mathrm{~kg}\left({ }^{(1)}\right.$ in Table 3) of refractory aerosol in the vortex column between 85 and $49 \mathrm{hPa}$ for EUPLEX. The ESSenCe case with estimated $21.3 \times 10^{6} \mathrm{~kg}\left({ }^{(2)}\right.$ in Table 3 ) of refractory particulate matter between 101 and $56 \mathrm{hPa}$ may provide a reference for the conditions when the vortex air is not yet influenced by major particle import from above during the current winter. The mean particle volume derived from the MSP size distribution (Bardeen et al., 2008) is three orders of magnitude below corresponding values derived from the upper limit size distributions. Thus, the lowermost estimate generally yields a refractory aerosol mass which is a factor of 1000 less (Table 4) than obtained from the upper limit within the vortex. The largest estimated mass in the probed vortex column comes from the RECONCILE measurements ( ${ }^{(3)}$ in Table 3 ), which are dominated by data from March, i.e., the late Arctic winter.

Within a pressure range of $100-67 \mathrm{hPa}$ the derived refractory aerosol masses from RECONCILE and ESSenCe are directly comparable. Presuming that the vortices undergo similar developments throughout the different winters (which in reality is not the case) the mass difference constitutes an enhancement of refractory aerosol by a factor of 4.5 during three months from December through March (ratio of (4) and ${ }^{(5)}$ in Table 3 and of ${ }^{(6)}$ and (7) in Table 4). With the mean upper limit of this estimate the differential enhancement ranges at $37.5 \times 10^{6} \mathrm{~kg}$ (difference between ${ }^{(4)}$ and (5) in Table 3) and correspondingly for the lowermost limit
$23.3 \times 10^{3} \mathrm{~kg}$ (difference between ${ }^{(6)}$ and (7) in Table 4) of refractory aerosol material within the vortex over the course of a winter.

Indeed, our observations made during ESSenCe most likely represent the conditions within the lower vortex region prior to the arrival of additional refractory particles from above. Assuming the simulation of Plumb et al. (2002) to be realistic, and since the air mass is twice as large in the column 67 to $1 \mathrm{hPa}$ as in the observed column 100 to $67 \mathrm{hPa}$, we estimate that at the end of the Arctic winter about $10-30 \%$ of the mesospheric air mass contributing to the entire vortex volume is to be found in the measurement region below $470 \mathrm{~K}$ (see Fig. 6 in Plumb et al., 2002). We assume further that the increase by a factor of 4.5 in the observed particle mass between 100 and $67 \mathrm{hPa}$ from midDecember to late winter can be attributed to the downward transport of refractory particles. The outflow of these particles at the vortex bottom may be negligible compared to the import from aloft. Hence, applying division by 0.3 and 0.1 to the mass enhancement obtained within the probed vortex regime, the particle import from the mesosphere is inferred, with an uppermost (lowermost) limit over the entire vortex of about ${ }^{(8)} 125-375 \times 10^{6} \mathrm{~kg}\left(77-230 \times 10^{3} \mathrm{~kg}\right)$ for the RECONCILE winter 2009/2010. 
Table 4. Lowermost boundary for the estimates of the integrated refractory aerosol mass $M_{\mathrm{nv}}$ in the vortex. Assumptions are the same as for previous calculation (cf. Sect. 6), as are the averaged vortex cross section areas from CLaMS as a function of $\Theta$. This mass estimate is determined by a size distribution of meteoritic ablation material only over the winter pole resulting from numerical studies (Bardeen et al., 2008). Vertical coordinates are given as provided in Table 2 . Uncertainty factors of $\left(\sqrt{M_{\mathrm{nv}}^{\max } / M_{\mathrm{nv}}^{\min }}\right)$ are applied to cover the extremes of the involved uncertainties. Indices ${ }^{(*)}$ simplify the traceability of the data's origin in the text.

\begin{tabular}{|c|c|c|c|c|c|c|}
\hline \multirow[b]{3}{*}{$\Theta$ in $\mathrm{K}$} & \multicolumn{6}{|c|}{$\begin{array}{l}\text { Altitude-resolved mass of refractory aerosol based on } \\
\text { modeled size distribution of meteoritic ablation material (Bardeen et al., 2008) }\end{array}$} \\
\hline & \multicolumn{2}{|c|}{ EUPLEX } & \multicolumn{2}{|c|}{ RECONCILE } & \multicolumn{2}{|c|}{ ESSenCe } \\
\hline & $p$ range in $\mathrm{hPa}$ & $M_{\mathrm{nv}}$ in $\mathrm{kg}$ & $p$ range in $\mathrm{hPa}$ & $M_{\mathrm{nv}}$ in $\mathrm{kg}$ & $p$ range in $\mathrm{hPa}$ & $M_{\mathrm{nv}}$ in $\mathrm{kg}$ \\
\hline 400 & - & - & $131-119$ & $4.1 \times 10^{3}$ & $101-89$ & $1.6 \times 10^{3}$ \\
\hline 410 & $85-77$ & $2.7 \times 10^{3}$ & $119-108$ & $1.4 \times 10^{3}$ & $89-79$ & $1.5 \times 10^{3}$ \\
\hline 420 & $77-70$ & $3.3 \times 10^{3}$ & 108-98 & $2.9 \times 10^{3}$ & $79-72$ & $1.7 \times 10^{3}$ \\
\hline 430 & $70-64$ & $3.5 \times 10^{3}$ & $98-90$ & $4.3 \times 10^{3}$ & $72-66$ & $1.8 \times 10^{3}$ \\
\hline 440 & $64-60$ & $3.5 \times 10^{3}$ & $90-83$ & $5.4 \times 10^{3}$ & $66-62$ & $1.9 \times 10^{3}$ \\
\hline 450 & $60-57$ & $3.2 \times 10^{3}$ & $83-77$ & $6.2 \times 10^{3}$ & $62-58$ & $1.7 \times 10^{3}$ \\
\hline 460 & $57-55$ & $3.0 \times 10^{3}$ & $77-72$ & $6.8 \times 10^{3}$ & $58-56$ & $1.6 \times 10^{3}$ \\
\hline 470 & $55-53$ & $2.7 \times 10^{3}$ & $72-67$ & $7.1 \times 10^{3}$ & - & - \\
\hline 480 & $53-51$ & $2.4 \times 10^{3}$ & - & - & - & - \\
\hline 490 & $51-50$ & $2.1 \times 10^{3}$ & - & - & - & - \\
\hline 500 & $50-49$ & $1.8 \times 10^{3}$ & - & - & - & - \\
\hline Total sum & & $28.3 \times 10^{3}$ & & $41.5 \times 10^{3}$ & & $14.7 \times 10^{3}$ \\
\hline Uncertainty factor & & 2.3 & & 2.1 & & 2.1 \\
\hline Sum $(100-67 \mathrm{hPa})$ & & $9.6 \times 10^{3}$ & & (6) $29.8 \times 10^{3}$ & & (7) $6.5 \times 10^{3}$ \\
\hline Uncertainty factor & & 2.1 & & 2.1 & & 1.9 \\
\hline
\end{tabular}

\subsubsection{Constraining the size distribution of the vortex refractory aerosol}

The expected global influx of meteoritic material is about $110 \times 10^{3} \mathrm{~kg}$ per day (Love and Brownlee, 1993). Thus, per year up to ${ }^{(9)} 40 \times 10^{6} \mathrm{~kg}$ of meteoritic material may be deposited in the mesosphere. Parts of the recently deposited aerosol material may remain in the mesosphere for several years (Dhomse et al., 2013). Nevertheless, a certain fraction of the recently deposited material may descend out of the mesosphere due to the vortex-induced subsidence during the next polar winter. When the vortex disintegrates in early spring, the particles are horizontally spread towards midlatitudes over the entire vertical extension of the former vortex column. Over the following seasons, until a new vortex can form, a certain fraction of particles may remain in the region above the pole. This fraction is available for incorporation into the newly forming vortex leading to further descent of particles. Finally, these particles reach the lowermost part of the vortex at $\Theta<500 \mathrm{~K}$ ahead of the newly incoming mesospheric air in early winter. However, for a balanced mass budget, the amount of material exiting the mesosphere towards the stratosphere should be in the range of the mesospheric input. Otherwise the meteoritic ablation material would accumulate in the mesosphere.
Thus, assuming a steady state situation and symmetry between the two hemispheres, each polar vortex would remove half of the amount of the yearly influx $\left({ }^{(9)}\right.$, cf. above) over the course of a winter, i.e., $20 \times 10^{6} \mathrm{~kg}$. Consequently, the refractory aerosol mass calculated from the size distribution of MSPs at $30 \mathrm{~km}$ above the winter pole (Bardeen et al., 2008) yields values, i.e., $23.3 \times 10^{3} \mathrm{~kg}$ (difference between ${ }^{(6)}$ and (7) in Table 4), two orders of magnitude below the expected mass influx. One could speculate that the vertical removal of meteoritic material occurs more efficiently at lower latitudes than due to the polar vortices, but this would contradict the findings that, at the end of a polar winter, most of the mesospheric content has been ingested by the vortex (Plumb et al., 2002). Therefore, the meteoritic ablation material is most likely drained to a large extent out of the mesosphere via the winter vortex. Consequently, the lowermost limit of our estimate seems to significantly underestimate the mass of refractory aerosol within the vortex. The size distribution of Bardeen et al. (2008), if adjusted for the size range of $d_{\mathrm{p}}>10 \mathrm{~nm}$ to be in accordance with $N_{10} \mathrm{nv}$, results in an in-vortex mass of refractory aerosol that is much smaller than could be expected. The resulting refractory aerosol mass from the size distribution of Bardeen et al. (2008) does not consider particles of sizes $d_{\mathrm{p}}<10 \mathrm{~nm}$ as these particles are not detected by the $N_{10}$ nv channel of COPAS and as their mass contribution is negligible. 
The size distributions that our estimates are based on only provide certain limits of such calculations. The true refractory aerosol size distribution, which is currently unknown, is very likely located somewhere in between the stratospheric background aerosol (Jaenicke, 1980; Wang et al., 1989; Deshler, 2008) and the numerically derived size distribution of MSPs (Bardeen et al., 2008). Nevertheless, the size distribution of the non-volatile remnants that remain, after the volatile compounds are evaporated, may not significantly differ from a typical size distribution of an aged, processed aerosol. Thus, it seems conceivable that the true refractory aerosol size distribution is very similar in shape to the size distribution of the stratospheric background aerosol, but this true refractory aerosol size distribution may peak at a certain smaller particle size. As a hypothesis, we assume here that the distribution peaks closer to our estimate's upper limit rather than being strongly shifted towards the estimate's lowermost limit. To sufficiently drain the expected meteoritic influx the true size distribution should result in an integrated refractory aerosol mass inside the entire vortex that is of the magnitude of the half-year influx, i.e., $20 \times 10^{6} \mathrm{~kg}$. Our estimate nearly approaches such a value with a tenth of the upper estimate's mean, i.e., $11.2-37.5 \times 10^{6} \mathrm{~kg}$ (tenth of ${ }^{(8)}$, cf. end of Sect. 6.4.2). This value still ranges at the lowermost extreme within this upper limit's uncertainty $\left({ }^{(10)}\right.$ and (11) in Table 3). However, the amount of the daily influx of meteoritic material is a matter of debate and could be a tenth (Plane, 2012) of what is specified by other references (Love and Brownlee, 1993; von Zahn, 2005).

There is the need to account for the probability that parts of the refractory aerosol in the Arctic vortex may originate from sources other than the meteoritic ablation in the mesosphere. These particles, e.g., from air and space traffic, sub-Pinatubo volcanism, biomass burning, etc., may contribute to the size distribution of refractory aerosol in the vortex. The negative correlation with $\mathrm{N}_{2} \mathrm{O}$ within the vortex indicates however that these refractory aerosols previously resided at high altitudes. The Brewer-Dobson circulation serves as the most important pathway leading the stratospheric material at high altitudes towards the pole, requiring these particles to survive a long-range transport. This condition is best fulfilled when the size of these refractory particle ranges within the accumulation mode $\left(0.1<d_{\mathrm{p}}<1 \mu \mathrm{m}\right)$, which has the longest atmospheric life times. The hypothesized contribution of submicron particles from other sources would be strongly supported if such particle species having an origin other than the meteoritic ablation were identified within the vortex.

In conclusion, estimations such as ours bear many uncertainties, but this clearly shows that comprehensive in situ investigations are necessary with respect to the different sources and transport mechanisms of refractory aerosol in the stratosphere to eliminate the current ambiguities. Also such in situ measurements of refractory aerosols at high altitudes may be used for refining the boundary conditions of numerical models simulating the vortex dynamics.

\section{Summary and conclusions}

Inside the Arctic vortex up to 8 of 11 particles with diameters larger than $10 \mathrm{~nm}$ and smaller than about $1 \mu \mathrm{m}$ were observed to consist of, or contain, non-volatile material. During three Arctic winter seasons of the years 2003, 2010 and 2011 this observation was repeatedly made in qualitative agreement. This agreement leads to the conclusion that the import of refractory aerosol material in the Arctic polar winter is a regular feature. We surmise that earlier observations of increased aerosol number concentration inside the Arctic vortex at about $20 \mathrm{~km}$ altitude (Wilson et al., 1990) and above $20 \mathrm{~km}$ (Hofmann et al., 1990) also comprise refractory aerosol and that new particle formation by homogeneous nucleation at the considered high altitudes plays a less crucial role than previously thought.

The quantity of refractory aerosols inside the vortex is connected to the transport history of air masses entering the vortex upper boundary from aloft, which includes air that could originate from as high as the mesosphere. Particle mixing ratios (up to 150 of non-volatile particles per milligram air) and the fraction of non-volatile particles (up to $75 \%$ ) are highest, where the air mass content of nitrous oxide $\left(\mathrm{N}_{2} \mathrm{O}\right)$ is lowest (here down to $70 \mathrm{nmol} \mathrm{mol}^{-1}$ ). The largest amounts of refractory aerosol inside the vortex appear in late winter (March), while in early winter (December) the bulk import from the upper stratosphere or mesosphere has apparently not yet reached the lower vortex observation region. In general the observed evolution of refractory particles and their correlation with the conserved tracer $\mathrm{N}_{2} \mathrm{O}$ in the Arctic vortex are in accord with current understanding of tracer transport and with the theory of tracer-tracer correlations (Plumb et al., 2002; Plumb, 2007). Based on this evolution of vertical profiles and correlations with $\mathrm{N}_{2} \mathrm{O}$ we suggest here that, apart from mean subsidence, transport of refractory aerosol to the lower vortex may be significantly driven by diabatic dispersion resulting from differential subsidence and mixing within the vortex. As shown here, until late March the refractory aerosol from high altitudes reaches down to the vortex bottom at about $400 \mathrm{~K}$, which could not be explained to result only from the slow mean subsidence in the lower vortex. At the end of March, the downward motion inside the Arctic vortex diminishes. Later the vortex dissolves, releasing the ingested material for mixing towards midlatitudes. The vortex can thus be understood as a temporary stratospheric reservoir of refractory aerosol material imported from aloft.

The abundance of refractory aerosol in the winter vortex is significantly driven by (a) the source strength (ablation of penetrating meteorites, volcanic activity, or other sources) for the aerosol material; (b) Rossby and gravity waves driving the meridional circulations in the mesosphere and stratosphere, including the polar winter descent of air from high altitudes; and (c) the vortex stability, as mid-winter stratospheric warmings and vortex breakup facilitate air mass ex- 
change across the vortex boundary resulting in dilution of the vortex with air from lower latitudes.

It can be assumed that over the course of a winter season the import of refractory aerosol due to the winter vortex subsidence and diabatic dispersion also occurs in the Antarctic. Recent studies (Campbell and Deshler, 2014) indicate that occasionally new particle formation contributes to the Antarctic aerosol loading at altitudes of $21-24 \mathrm{~km}$. Nevertheless, also in the Antarctic, but above $24 \mathrm{~km}$, fractions of up to $80 \%$ of non-volatile particles were observed.

From our measurements we have estimated the total refractory aerosol mass in the lowermost vortex and further the aerosol mass imported from aloft into the pressure interval 100-67 hPa between early (ESSenCe) and late winter (RECONCILE). This estimate yields an enhancement of the refractory aerosol mass by a factor of 4.5 at the lowermost vortex $(100-67 \mathrm{hPa})$ toward the end of an Arctic winter. These estimates are further extrapolated to an estimate of the integrated refractory aerosol mass import into the entire Arctic winter vortex, which is finally evaluated by comparison with the assumed influx of meteoritic aerosol material. Of course, large uncertainties are inherent in this approach. The largest ambiguity arises from the unknown size distribution of refractory aerosol within the Arctic vortex. However, the value for the daily influx of meteoritic material is still a matter of discussion, and it is still possible that non-meteoritic sources contribute to the vortex refractory aerosol composition. Nonetheless, within the given uncertainties our estimate of the integrated refractory aerosol mass reveals that the import into the Arctic winter vortex could in principle balance the assumed meteoritic mass influx into the mesosphere.

Consequently, the remaining unresolved issues are connected with the chemical composition, the morphology, and physical nature of the refractory particles entering the polar vortex for unambiguously specifying their origin. The amount and role of anthropogenic components from space debris, rocket launches and exhaust of high flying aircraft is not well enough quantified. Even contributions of soil materials continuously released by sub-Pinatubo volcanism (e.g., Souffriere Hills, Nabro) and other ground sources, such as biomass burning, possibly need to be considered. Knowledge of the aerosol properties is also essential for conclusions concerning the particle sources as well as their role and effectiveness in PSC and, ultimately, in cirrus cloud formation. Besides the need for more in situ measurements at high altitudes we would like to emphasize the importance of laboratory experiments on heterogeneous nucleation of PSCs (particularly for nitric acid trihydrate - NAT) on the observed refractory materials including particles coated with $\mathrm{H}_{2} \mathrm{SO}_{4}$, $\mathrm{HNO}_{3}, \mathrm{H}_{2} \mathrm{O}$, and possibly other condensable materials.
Acknowledgements. The contributions from the technical staff at the workshops of the MPI for Chemistry and the Institute for Physics of the Atmosphere (Mainz University), as well as the Myasishchev Design Bureau (MDB) were crucial and essential. In particular we acknowledge support of T. Böttger, M. Flanz and W. Schneider. We very much thank the MDB crew and the M55-Geophysica pilots. Thanks to R. E. Jubb for proofreading the manuscript. We thank 4 anonymous referees, A. James and P. Spichtinger for their helpful suggestions and support. ESSenCe was in parts supported by the German Research Foundation (DFG) under contract HALO-SPP 1294/GR 3786. Some of our research leading to the presented results received funding from the European Research Council under the European Union's Seventh Framework Program (FP/2007-2013)/ERC Grant Agreement No. 321040 (EXCATRO). RECONCILE was supported by ESA, BMBF, and the EU (contract RECONCILE-226365-FP7-ENV-2008-1). Further financial support was provided by internal sources of the Johannes Gutenberg University and the Max Planck Institute for Chemistry in Mainz, as well as the Karlsruhe Institute for Technology and Forschungszentrum Jülich GmbH (both for ESSenCe). The CLaMS simulations were performed using computing time granted on the supercomputer JUROPA at Jülich Supercomputing Centre (JSC) under the VSR project ID JICG11. We dedicate this publication to our colleague and friend, Cornelius Schiller, who was involved in EUPLEX and RECONCILE, and who passed away so untimely on 3 March 2012.

Edited by: Y. Rudich

\section{References}

Bardeen, C. G., Toon, O. B., Jensen, E. J., Marsh, D. R., and Harvey, V. L.: Numerical simulations of the three-dimensional distribution of meteoric dust in the mesosphere and upper stratosphere, J. Geophys. Res. Atmos., 113, D17202, doi:10.1029/2007jd009515, 2008.

Biermann, U. M., Presper, T., Koop, T., Mossinger, J., Crutzen, P. J., and Peter, T.: The unsuitability of meteoritic and other nuclei for polar stratospheric cloud freezing, Geophys. Res. Lett., 23, 1693-1696, doi:10.1029/96g101577, 1996.

Borrmann, S., Dye, J. E., Baumgardner, D., Proffitt, M. H., Margitan, J. J., Wilson, J. C., Jonsson, H. H., Brock, C. A., Loewenstein, M., Podolske, J. R., and Ferry, G. V.: Aerosols as Dynamical Tracers in the Lower Stratosphere - Ozone Versus Aerosol Correlation after the Mount-Pinatubo Eruption, J. Geophys. Res. Atmos., 100, 11147-11156, doi:10.1029/95jd00016, 1995.

Borrmann, S., Thomas, A., Rudakov, V., Yushkov, V., Lepuchov, B., Deshler, T., Vinnichenko, N., Khattatov, V., and Stefanutti, L.: Stratospheric aerosol measurements in the Arctic winter of 1996/1997 with the M-55 Geophysika high-altitude research aircraft, Tellus B, 52, 1088-1103, doi:10.1034/j.16000889.2000.00100.x, 2000.

Borrmann, S., Kunkel, D., Weigel, R., Minikin, A., Deshler, T., Wilson, J. C., Curtius, J., Volk, C. M., Homan, C. D., Ulanovsky, A., Ravegnani, F., Viciani, S., Shur, G. N., Belyaev, G. V., Law, K. S., and Cairo, F.: Aerosols in the tropical and subtropical UT/LS: insitu measurements of submicron particle abundance and volatility, Atmos. Chem. Phys., 10, 5573-5592, doi:10.5194/acp-105573-2010, 2010. 
Brock, C. A., Hamill, P., Wilson, J. C., Jonsson, H. H., and Chan, K. R.: Particle Formation in the Upper Tropical Troposphere: A Source of Nuclei for the Stratospheric Aerosol, Science, 270, 1650-1653, doi:10.2307/2887916, 1995.

Campbell, P., and Deshler, T.: Condensation nuclei measurements in the midlatitude (1982-2012) and Antarctic (1986-2010) stratosphere between 20 and $35 \mathrm{~km}$, J. Geophys. Res. Atmos., 119, 137-152, doi:10.1002/2013jd019710, 2014.

Curtius, J., Weigel, R., Vössing, H.-J., Wernli, H., Werner, A., Volk, C.-M., Konopka, P., Krebsbach, M., Schiller, C., Roiger, A., Schlager, H., Dreiling, V., and Borrmann, S.: Observations of meteoric material and implications for aerosol nucleation in the winter Arctic lower stratosphere derived from in situ particle measurements, Atmos. Chem. Phys., 5, 3053-3069, doi:10.5194/acp-5-3053-2005, 2005.

Cziczo, D. J., Thomson, D. S., and Murphy, D. M.: Ablation, flux, and atmospheric implications of meteors inferred from stratospheric aerosol, Science, 291, 1772-1775, 2001.

Dee, D. P., Uppala, S. M., Simmons, A. J., Berrisford, P., Poli, P., Kobayashi, S., Andrae, U., Balmaseda, M. A., Balsamo, G., Bauer, P., Bechtold, P., Beljaars, A. C. M., van de Berg, L., Bidlot, J., Bormann, N., Delsol, C., Dragani, R., Fuentes, M., Geer, A. J., Haimberger, L., Healy, S. B., Hersbach, H., Hólm, E. V., Isaksen, L., Kållberg, P., Köhler, M., Matricardi, M., McNally, A. P., Monge-Sanz, B. M., Morcrette, J. J., Park, B. K., Peubey, C., de Rosnay, P., Tavolato, C., Thépaut, J. N., and Vitart, F.: The ERA-Interim reanalysis: configuration and performance of the data assimilation system, Q. J. Roy. Meteor. Soc., 137, 553-597, doi:10.1002/qj.828, 2011.

Deshler, T.: A review of global stratospheric aerosol: Measurements, importance, life cycle, and local stratospheric aerosol, Atmos. Res., 90, 223-232, doi:10.1016/j.atmosres.2008.03.016, 2008.

Dhomse, S. S., Saunders, R. W., Tian, W., Chipperfield, M. P., and Plane, J. M. C.: Plutonium-238 observations as a test of modeled transport and surface deposition of meteoric smoke particles, Geophys. Res. Lett., 40, 4454-4458, doi:10.1002/grl.50840, 2013.

Dörnbrack, A., Pitts, M. C., Poole, L. R., Orsolini, Y. J., Nishii, K., and Nakamura, H.: The 2009-2010 Arctic stratospheric winter - general evolution, mountain waves and predictability of an operational weather forecast model, Atmos. Chem. Phys., 12, 3659-3675, doi:10.5194/acp-12-3659-2012, 2012.

Engel, A., Möbius, T., Haase, H. P., Bönisch, H., Wetter, T., Schmidt, U., Levin, I., Reddmann, T., Oelhaf, H., Wetzel, G., Grunow, K., Huret, N., and Pirre, M.: Observation of mesospheric air inside the arctic stratospheric polar vortex in early 2003, Atmos. Chem. Phys., 6, 267-282, doi:10.5194/acp-6-2672006, 2006.

Engel, I., Luo, B. P., Pitts, M. C., Poole, L. R., Hoyle, C. R., Grooss, J. U., Dornbrack, A., and Peter, T.: Heterogeneous formation of polar stratospheric clouds - Part 2: Nucleation of ice on synoptic scales, Atmos. Chem. Phys., 13, 10769-10785, doi:10.5194/acp13-10769-2013, 2013.

Fahey, D. W., Kelly, K. K., Kawa, S. R., Tuck, A. F., Loewenstein, M., Chan, K. R., and Heidt, L. E.: Observations of Denitrification and Dehydration in the Winter Polar Stratospheres, Nature, 344, 321-324, doi:10.1038/344321a0, 1990.
Fisher, M., O’Neill, A., and Sutton, R.: Rapid descent of mesospheric air into the stratospheric polar vortex, Geophys. Res. Lett., 20, 1267-1270, doi:10.1029/93g101104, 1993.

Frey, W., Borrmann, S., Kunkel, D., Weigel, R., de Reus, M., Schlager, H., Roiger, A., Voigt, C., Hoor, P., Curtius, J., Kramer, M., Schiller, C., Volk, C. M., Homan, C. D., Fierli, F., Di Donfrancesco, G., Ulanovsky, A., Ravegnani, F., Sitnikov, N. M., Viciani, S., D’Amato, F., Shur, G. N., Belyaev, G. V., Law, K. S., and Cairo, F.: In situ measurements of tropical cloud properties in the West African Monsoon: upper tropospheric ice clouds, Mesoscale Convective System outflow, and subvisual cirrus, Atmos. Chem. Phys., 11, 5569-5590, doi:10.5194/acp-11-55692011, 2011.

Funke, B., García-Comas, M., López-Puertas, M., Glatthor, N., Stiller, G. P., von Clarmann, T., Semeniuk, K., and McConnell, J. C.: Enhancement of $\mathrm{N}_{2} \mathrm{O}$ during the October-November 2003 solar proton events, Atmos. Chem. Phys., 8, 3805-3815, doi:10.5194/acp-8-3805-2008, 2008.

Gabrielli, P., Barbante, C., Plane, J. M. C., Varga, A., Hong, S., Cozzi, G., Gaspari, V., Planchon, F. A. M., Cairns, W., Ferrari, C., Crutzen, P., Cescon, P., and Boutron, C. F.: Meteoric smoke fallout over the Holocene epoch revealed by iridium and platinum in Greenland ice, Nature, 432, 1011-1014, doi:10.1038/Nature03137, 2004.

Greenblatt, J. B., Jost, H.-J., Loewenstein, M., Podolske, J. R., Hurst, D. F., Elkins, J. W., Schauffler, S. M., Atlas, E. L., Herman, R. L., Webster, C. R., Bui, T. P., Moore, F. L., Ray, E. A., Oltmans, S., Vömel, H., Blavier, J.-F., Sen, B., Stachnik, R. A., Toon, G. C., Engel, A., Müller, M., Schmidt, U., Bremer, H., Pierce, R. B., Sinnhuber, B.-M., Chipperfield, M., and Lefèvre, F.: Tracer-based determination of vortex descent in the 1999/2000 Arctic winter, J. Geophys. Res. Atmos., 107, 8279, doi:10.1029/2001jd000937, 2002a.

Greenblatt, J. B., Jost, H.-J., Loewenstein, M., Podolske, J. R., Bui, T. P., Hurst, D. F., Elkins, J. W., Herman, R. L., Webster, C. R., Schauffler, S. M., Atlas, E. L., Newman, P. A., Lait, L. R., Müller, M., Engel, A., and Schmidt, U.: Defining the polar vortex edge from an $\mathrm{N}_{2} \mathrm{O}$ : potential temperature correlation, J. Geophys. Res. Atmos., 107, 8268, doi:10.1029/2001jd000575, 2002b.

Grooß, J. U., Engel, I., Borrmann, S., Frey, W., Günther, G., Hoyle, C. R., Kivi, R., Luo, B. P., Molleker, S., Peter, T., Pitts, M. C., Schlager, H., Stiller, G., Vömel, H., Walker, K. A., and Müller, R.: Nitric acid trihydrate nucleation and denitrification in the Arctic stratosphere, Atmos. Chem. Phys., 14, 1055-1073, doi:10.5194/acp-14-1055-2014, 2014.

Günther, G., Müller, R., von Hobe, M., Stroh, F., Konopka, P., and Volk, C. M.: Quantification of transport across the boundary of the lower stratospheric vortex during Arctic winter 2002/2003, Atmos. Chem. Phys., 8, 3655-3670, doi:10.5194/acp-8-36552008, 2008.

Haynes, P. and Shuckburgh, E.: Effective diffusivity as a diagnostic of atmospheric transport: 1. Stratosphere, J. Geophys. Res. Atmos., 105, 22777-22794, doi:10.1029/2000jd900093, 2000.

Hinds, W. C.: Aerosol Technology: Properties, Behavior, and Measurement of airborne Particles (2nd edition), 97-100, 1999.

Hofmann, D. J., Deshler, T., Arnold, F., and Schlager, H.: Balloon Observations of Nitric-Acid Aerosol Formation in the Arctic Stratosphere .2. Aerosol, Geophys. Res. Lett., 17, 1279-1282, doi:10.1029/G1017i009p01279, 1990. 
Holton, J. R., Haynes, P. H., McIntyre, M. E., Douglass, A. R., Rood, R. B., and Pfister, L.: Stratosphere-troposphere exchange, Rev. Geophys., 33, 403-439, 1995.

Homan, C. D., Volk, C. M., Kuhn, A. C., Werner, A., Baehr, J., Viciani, S., Ulanovski, A., and Ravegnani, F.: Tracer measurements in the tropical tropopause layer during the AMMA/SCOUT$\mathrm{O}_{3}$ aircraft campaign, Atmos. Chem. Phys., 10, 3615-3627, doi:10.5194/acp-10-3615-2010, 2010.

Hösen, E., Volk, C. M., Grooß, J.-U., Günther, G., and Werner, A.: The vortex index: an empirical origin of air tracer based on longlived tracer measurements, submitted to Atmos. Chem. Phys. Discuss., 2014.

Hoyle, C. R., Engel, I., Luo, B. P., Pitts, M. C., Poole, L. R., Grooss, J. U., and Peter, T.: Heterogeneous formation of polar stratospheric clouds - Part 1: Nucleation of nitric acid trihydrate (NAT), Atmos. Chem. Phys., 13, 9577-9595, doi:10.5194/acp13-9577-2013, 2013.

Hunten, D. M., Turco, R. P., and Toon, O. B.: Smoke and Dust Particles of Meteoric Origin in the Mesosphere and Stratosphere, J. Atmos. Sci., 37, 1342-1357, 1980.

Jaenicke, R.: Atmospheric Aerosols and Global Climate, J. Aerosol Sci., 11, 577-588, doi:10.1016/0021-8502(80)90131-7, 1980.

Janches, D., Mathews, J. D., Meisel, D. D., and Zhou, Q. H.: Micrometeor Observations Using the Arecibo $430 \mathrm{MHz}$ Radar: I. Determination of the Ballistic Parameter from Measured Doppler Velocity and Deceleration Results, Icarus, 145, 53-63, doi:10.1006/icar.1999.6330, 2000.

Jones, J. and Kaiser, T. R.: The effects of thermal radiation, conduction and metoriod heat capacity on meteoric ablation, Mon. Not. R. Astron. Soc., 133, 411-420, 1966.

Kalashnikova, O., Horányi, M., Thomas, G. E., and Toon, O. B.: Meteoric smoke production in the atmosphere, Geophys. Res. Lett., 27, 3293-3296, doi:10.1029/1999gl011338, 2000.

Kaufmann, M., Blank, J., Guggenmoser, T., Ungermann, J., Engel, A., Ern, M., Friedl-Vallon, F., Gerber, D., Grooss, J. U., Guenther, G., Höpfner, M., Kleinert, A., Latzko, Th., Maucher, G., Neubert, T., Nordmeyer, H., Oelhaf, H., Olschewski, F., Orphal, J., Preusse, P., Schlager, H., Schneider, H., Schuettemeyer, D., Stroh, F., Suminska-Ebersoldt, O., Vogel, B., Volk, C. M., Woiwode, W., and Riese, M.: Retrieval of three-dimensional small scale structures in upper tropospheric/lower stratospheric composition as measured by GLORIA, Atmos. Meas. Tech. Discuss., 7, 4229-4274, doi:10.5194/amtd-7-4229-2014, 2014.

Konopka, P., Günther, G., Müller, R., dos Santos, F. H. S., Schiller, C., Ravegnani, F., Ulanovsky, A., Schlager, H., Volk, C. M., Viciani, S., Pan, L. L., McKenna, D. S., and Riese, M.: Contribution of mixing to upward transport across the tropical tropopause layer (TTL), Atmos. Chem. Phys., 7, 3285-3308, doi:10.5194/acp-7-3285-2007, 2007.

Love, S. G. and Brownlee, D. E.: A Direct Measurement of the Terrestrial Mass Accretion Rate of Cosmic Dust, Science, 262, 550-553, doi:10.1126/science.262.5133.550, 1993.

Mann, G. W., Davies, S., Carslaw, K. S., and Chipperfield, M. P.: Factors controlling Arctic denitrification in cold winters of the 1990s, Atmos. Chem. Phys., 3, 403-416, doi:10.5194/acp-3-4032003, 2003.

McKenna, D. S., Grooß, J.-U., Günther, G., Konopka, P., Müller, R., Carver, G., and Sasano, Y.: A new Chemical Lagrangian Model of the Stratosphere (CLaMS) 2. Formulation of chemistry scheme and initialization, J. Geophys. Res. Atmos., 107, ACH 4-1-ACH 4-14, doi:10.1029/2000jd000113, 2002a.

McKenna, D. S., Konopka, P., Grooß, J.-U., Günther, G., Müller, R., Spang, R., Offermann, D., and Orsolini, Y.: A new Chemical Lagrangian Model of the Stratosphere (CLaMS) 1. Formulation of advection and mixing, J. Geophys. Res. Atmos., 107, ACH 15-11-ACH 15-15, doi:10.1029/2000jd000114, 2002 b.

Megner, L., Siskind, D. E., Rapp, M., and Gumbel, J.: Global and temporal distribution of meteoric smoke: A two-dimensional simulation study, J. Geophys. Res. Atmos., 113, D03202, doi:10.1029/2007jd009054, 2008.

Molleker, S., Borrmann, S., Schlager, H., Luo, B., Frey, W., Klingebiel, M., Weigel, R., Ebert, M., Mitev, V., Matthey, R., Woiwode, W., Oelhaf, H., Dörnbrack, A., Stratmann, G., Grooß, J.U., Günther, G., Vogel, B., Müller, R., Krämer, M., Meyer, J., and Cairo, F.: Microphysical properties of synoptic-scale polar stratospheric clouds: in situ measurements of unexpectedly large $\mathrm{HNO}_{3}$-containing particles in the Arctic vortex, Atmos. Chem. Phys., 14, 10785-10801, doi:10.5194/acp-14-10785-2014, 2014.

Murphy, D. M., Froyd, K. D., Schwarz, J. P., and Wilson, J. C.: Observations of the chemical composition of stratospheric aerosol particles, Q. J. Roy. Meteor. Soc., 140, 1269-1278, doi:10.1002/qj.2213, 2013.

Nash, E. R., Newman, P. A., Rosenfield, J. E., and Schoeberl, M. R.: An objective determination of the polar vortex using Ertel's potential vorticity, J. Geophys. Res. Atmos., 101, 9471-9478, doi:10.1029/96jd00066, 1996.

Peter, T.: Microphysics and heterogeneous chemistry of polar stratospheric clouds, Annu. Rev. Phys. Chem., 48, 785-822, doi:10.1146/annurev.physchem.48.1.785, 1997.

Peter, T. and Grooß, J.-U.: Chapter 4 Polar Stratospheric Clouds and Sulfate Aerosol Particles: Microphysics, Denitrification and Heterogeneous Chemistry, in: Stratospheric Ozone Depletion and Climate Change, Roy. Soc. Chem., 108-144, 2012.

Peucker-Ehrenbrink, B.: Accretion of extraterrestrial matter during the last 80 million years and its effect on the marine osmium isotope record, Geochim. Cosmochim. Ac., 60, 3187-3196, doi:10.1016/0016-7037(96)00161-5, 1996.

Plane, J. M. C.: A time-resolved model of the mesospheric Na layer: constraints on the meteor input function, Atmos. Chem. Phys., 4, 627-638, doi:10.5194/acp-4-627-2004, 2004.

Plane, J. M. C.: Cosmic dust in the earth's atmosphere, Chem. Soc. Rev., 41, 6507-6518, 2012.

Plumb, R. A.: Tracer interrelationships in the stratosphere, Rev. Geophys., 45, RG4005, doi:10.1029/2005RG000179, 2007.

Plumb, R. A., Heres, W., Neu, J. L., Mahowald, N. M., del Corral, J., Toon, G. C., Ray, E., Moore, F., and Andrews, A. E.: Global tracer modeling during SOLVE: High-latitude descent and mixing, J. Geophys. Res. Atmos., 107, 8309, doi:10.1029/2001jd001023, 2002.

Prather, M. J. and Rodriguez, J. M.: Antarctic ozone: Meteoric control of $\mathrm{HNO}_{3}$, Geophys. Res. Lett., 15, 1-4, doi:10.1029/GL015i001p00001, 1988.

Randall, C. E., Harvey, V. L., Singleton, C. S., Bernath, P. F., Boone, C. D., and Kozyra, J. U.: Enhanced $\mathrm{NO}_{\mathrm{x}}$ in 2006 linked to strong upper stratospheric Arctic vortex, Geophys. Res. Lett., 33, L18811, doi:10.1029/2006g1027160, 2006.

Rapp, M. and Strelnikova, I.: Measurements of meteor smoke particles during the ECOMA-2006 campaign: 1. Particle detection by 
active photoionization, J. Atmos. Sol.-Terr. Phy., 71, 477-485, doi:10.1016/j.jastp.2008.06.002, 2009.

Rapp, M., Strelnikova, I., and Gumbel, J.: Meteoric smoke particles: Evidence from rocket and radar techniques, Adv. Space Res., 40, 809-817, doi:10.1016/j.asr.2006.11.021, 2007.

Ray, E. A., Moore, F. L., Elkins, J. W., Hurst, D. F., Romashkin, P. A., Dutton, G. S., and Fahey, D. W.: Descent and mixing in the 1999-2000 northern polar vortex inferred from in situ tracer measurements, J. Geophys. Res. Atmos., 107, 8285, doi:10.1029/2001jd000961, 2002.

Saunders, R. W., Möhler, O., Schnaiter, M., Benz, S., Wagner, R., Saathoff, H., Connolly, P. J., Burgess, R., Murray, B. J., Gallagher, M., Wills, R., and Plane, J. M. C.: An aerosol chamber investigation of the heterogeneous ice nucleating potential of refractory nanoparticles, Atmos. Chem. Phys., 10, 1227-1247, doi:10.5194/acp-10-1227-2010, 2010.

Saunders, R. W., Dhomse, S., Tian, W. S., Chipperfield, M. P., and Plane, J. M. C.: Interactions of meteoric smoke particles with sulphuric acid in the Earth's stratosphere, Atmos. Chem. Phys., 12, 4387-4398, doi:10.5194/acp-12-4387-2012, 2012.

Shur, G. N., Sitnikov, N. M., and Drynkov, A. V.: A mesoscale structure of meteorological fields in the tropopause layer and in the lower stratosphere over the southern tropics (Brazil), Russ. Meteorol. Hydrol., 32, 487-494, doi:10.3103/s106837390708002x, 2007.

Sokolov, L. and Lepuchov, B.: Protocol of interaction between Unit for Connection with Scientific Equipment (UCSE) and onboard scientific equipment of Geophysica aircraft (second edition), Myasishchev Design Bureau (MDB), 1998.

Solomon, S.: Stratospheric ozone depletion: A review of concepts and history, Rev. Geophys., 37, 275-316, doi:10.1029/1999rg900008, 1999.

Spang, R., Stroh, F., von Hobe, M., Gerber, D., Moyna, B., Oldfield, M., Rea, S., Reburn, J., Siddans, R., Kerridge, B., Oelhaf, H., and Woiwode, W.: Data Acquisition Report of the PremierEX Scientific Flights, Final Report for ESTEC, Contract No. 2670/09/NL/CT “PREMIER Experiment”, 3139, 3151, available at: https://earth.esa.int/documents/10174/87248/ PremierEX_FinalReport_v2.pdf, 25 May 2012.

Stefanutti, L., Sokolov, L., Balestri, S., MacKenzie, A. R., and Khattatov, V.: The M-55 Geophysica as a Platform for the Airborne Polar Experiment, J. Atmos. Ocean. Technol., 16, 1303-1312, 10.1175/1520-0426(1999)016<1303:tmgaap>2.0.CO;2, 1999.

Strelnikova, I., Rapp, M., Strelnikov, B., Baumgarten, G., Brattli, A., Svenes, K., Hoppe, U. P., Friedrich, M., Gumbel, J., and Williams, B. P.: Measurements of meteor smoke particles during the ECOMA-2006 campaign: 2. Results, J. Atmos. Sol.-Terr. Phys., 71, 486-496, doi:10.1016/j.jastp.2008.07.011, 2009.

Vogel, B., Konopka, P., Grooß, J. U., Müller, R., Funke, B., LópezPuertas, M., Reddmann, T., Stiller, G., von Clarmann, T., and Riese, M.: Model simulations of stratospheric ozone loss caused by enhanced mesospheric $\mathrm{NO}_{\mathrm{x}}$ during Arctic Winter 2003/2004, Atmos. Chem. Phys., 8, 5279-5293, doi:10.5194/acp-8-52792008, 2008.

Voigt, C., Schlager, H., Luo, B. P., Dornbrack, A. D., Roiger, A., Stock, P., Curtius, J., Vossing, H., Borrmann, S., Davies, S., Konopka, P., Schiller, C., Shur, G., and Peter, T.: Nitric Acid Trihydrate (NAT) formation at low NAT supersaturation in Polar Stratospheric Clouds (PSCs), Atmos. Chem. Phys., 5, 1371-1380, doi:10.5194/acp-5-1371-2005, 2005.

von Hobe, M., Bekki, S., Borrmann, S., Cairo, F., D'Amato, F., Di Donfrancesco, G., Dörnbrack, A., Ebersoldt, A., Ebert, M., Emde, C., Engel, I., Ern, M., Frey, W., Genco, S., Griessbach, S., Grooß, J. U., Gulde, T., Günther, G., Hösen, E., Hoffmann, L., Homonnai, V., Hoyle, C. R., Isaksen, I. S. A., Jackson, D. R., Jánosi, I. M., Jones, R. L., Kandler, K., Kalicinsky, C., Keil, A., Khaykin, S. M., Khosrawi, F., Kivi, R., Kuttippurath, J., Laube, J. C., Lefèvre, F., Lehmann, R., Ludmann, S., Luo, B. P., Marchand, M., Meyer, J., Mitev, V., Molleker, S., Müller, R., Oelhaf, H., Olschewski, F., Orsolini, Y., Peter, T., Pfeilsticker, K., Piesch, C., Pitts, M. C., Poole, L. R., Pope, F. D., Ravegnani, F., Rex, M., Riese, M., Röckmann, T., Rognerud, B., Roiger, A., Rolf, C., Santee, M. L., Scheibe, M., Schiller, C., Schlager, H., Siciliani de Cumis, M., Sitnikov, N., Søvde, O. A., Spang, R., Spelten, N., Stordal, F., Sumińska-Ebersoldt, O., Ulanovski, A., Ungermann, J., Viciani, S., Volk, C. M., vom Scheidt, M., von der Gathen, P., Walker, K., Wegner, T., Weigel, R., Weinbruch, S., Wetzel, G., Wienhold, F. G., Wohltmann, I., Woiwode, W., Young, I. A. K., Yushkov, V., Zobrist, B., and Stroh, F.: Reconciliation of essential process parameters for an enhanced predictability of Arctic stratospheric ozone loss and its climate interactions (RECONCILE): activities and results, Atmos. Chem. Phys., 13, 9233-9268, doi:10.5194/acp-13-9233-2013, 2013

von Zahn, U.: The total mass flux of meteoroids into the Earth's upper atmosphere, 17th ESA Symposium on European Rocket and Balloon Programmes and Related Research, 30 May-2 June 2005, Sandefjord, Norway. Ed.: Barbara Warmbein. ESA SP590, Noordwijk: ESA Publications Division, ISBN92-9092-9014, 33-39, 2005.

Waibel, A. E., Peter, T., Carslaw, K. S., Oelhaf, H., Wetzel, G., Crutzen, P. J., Poschl, U., Tsias, A., Reimer, E., and Fischer, H.: Arctic ozone loss due to denitrification, Science, 283 2064-2069, doi:10.1126/science.283.5410.2064, 1999.

Wang, P. H., McCormick, M. P., Swissler, T. J., Osborn, M. T., Fuller, W. H., and Yue, G. K.: Inference of Stratospheric Aerosol Composition and Size Distribution from Sage-II Satellite Measurements, J. Geophys. Res. Atmos., 94, 8435-8446, doi:10.1029/Jd094id06p08435, 1989.

Wegner, T., Grooss, J. U., von Hobe, M., Stroh, F., SuminskaEbersoldt, O., Volk, C. M., Hosen, E., Mitev, V., Shur, G., and Muller, R.: Heterogeneous chlorine activation on stratospheric aerosols and clouds in the Arctic polar vortex, Atmos. Chem. Phys., 12, 11095-11106, doi:10.5194/acp-12-11095-2012, 2012.

Weigel, R., Hermann, M., Curtius, J., Voigt, C., Walter, S., Böttger, T., Lepukhov, B., Belyaev, G., and Borrmann, S.: Experimental characterization of the COndensation PArticle counting System for high altitude aircraft-borne application, Atmos. Meas. Tech., 2, 243-258, doi:10.5194/amt-2-243-2009, 2009.

Weigel, R., Borrmann, S., Kazil, J., Minikin, A., Stohl, A., Wilson, J. C., Reeves, J. M., Kunkel, D., de Reus, M., Frey, W., Lovejoy, E. R., Volk, C. M., Viciani, S., D’ Amato, F., Schiller, C., Peter, T., Schlager, H., Cairo, F., Law, K. S., Shur, G. N., Belyaev, G. V., and Curtius, J.: In situ observations of new particle formation in the tropical upper troposphere: the role of clouds and the nucleation mechanism, Atmos. Chem. Phys., 11, 9983-10010, doi:10.5194/acp-11-9983-2011, 2011. 
Weinheimer, A. J., Walega, J. G., Ridley, B. A., Sachse, G. W., Anderson, B. E., and Collins, J. E.: Stratospheric Noy Measurements on the Nasa Dc-8 during Aase-Ii, Geophys. Res. Lett., 20, 2563-2566, doi:10.1029/93g102627, 1993.

Werner, A., Volk, C. M., Ivanova, E. V., Wetter, T., Schiller, C., Schlager, H., and Konopka, P.: Quantifying transport into the Arctic lowermost stratosphere, Atmos. Chem. Phys., 10, 11623-11639, doi:10.5194/acp-10-11623-2010, 2010.

Wilson, J. C., Stolzenburg, M. R., Clark, W. E., Loewenstein, M., Ferry, G. V., and Chan, K. R.: Measurements of Condensation Nuclei in the Airborne Arctic Stratospheric Expedition - Observations of Particle-Production in the Polar Vortex, Geophys. Res. Lett., 17, 361-364, doi:10.1029/G1017i004p00361, 1990.
Woiwode, W., Grooß, J.-U., Oelhaf, H., Molleker, S., Borrmann, S., Ebersoldt, A., Frey, W., Gulde, T., Khaykin, S., Maucher, G., Piesch, C., and Orphal, J.: Denitrification by large NAT particles: the impact of reduced settling velocities and hints on particle characteristics, Atmos. Chem. Phys. Discuss., 14, 5893-5927, doi:10.5194/acpd-14-5893-2014, 2014. 